\title{
Claes Johnson
} VIDAR THOMEE

\section{Error estimates for some mixed finite element} methods for parabolic type problems

RAIRO - Analyse numérique, tome $15, \mathrm{n}^{\mathrm{o}} 1$ (1981), p. 41-78.

$<$ http://www.numdam.org/item?id=M2AN_1981_15_1_41_0>

C AFCET, 1981, tous droits réservés.

L'accès aux archives de la revue «RAIRO - Analyse numérique » implique l'accord avec les conditions générales d'utilisation (http://www.numdam.org/ legal.php). Toute utilisation commerciale ou impression systématique est constitutive d'une infraction pénale. Toute copie ou impression de ce fichier doit contenir la présente mention de copyright.

\section{Numdam}




\title{
ERROR ESTIMATES \\ FOR SOME MIXED FINITE ELEMENT METHODS FOR PARABOLIC TYPE PROBLEMS $\left({ }^{*}\right)$
}

\author{
by Claes Johnson and Vidar Thomee $\left({ }^{1}\right)$
}

\begin{abstract}
We consider a class of mixed fintte element methods for second order elliptic problems introduced by Raviart and Thomas and generalize or give alternative proofs of previously known error estimates for such methods We then extend these results to the corresponding parabolic problems thereby obtaining estimates similar to those previously known for conventional finte element methods for parabolic problems We also obtain corresponding results for a mixed finte element method for the stationary and evolutionary Stokes' equations

Résumé - On considère une famille de methodes d'éléments finis mixtes pour les problèmes elliptiques du second ordre introduite par Raviart et Thomas, et on presente des généralisations, ou de nouvelles démonstrations, des estimations d'erreur connues auparavant pour ces méthodes On étend ensulte ces résultats aux problèmes paraboliques correspondants, et on obtient de cette façon des esttmations semblables à celles dejà connues pour les méthodes d'éléments fints conformes pour les problèmes paraboliques. On obtient aussi des résultats correspondants pour une méthode d'éléments fints mixtes pour les équations de Stokes, dans les cas stationnalre et d'evolution
\end{abstract}

\section{INTRODUCTION}

Mixed finite element methods for elliptic problems have been proposed and analyzed by several authors (see e.g. $[6,13,16,14,12]$ and others). The main purpose of this paper is to prove some error estimates for a class of such mixed methods when applied to the corresponding parabolic problems. These error estimates are similar to those obtained previously for conventional finite element methods ( $c f$. e.g. [4] and work quoted therein). We shall analyze in detail the effect of the finite element discretization in space and comment only briefly on time-discretization.

An outline of the paper is as follows: in Section 1 we consider a class of mixed finite element methods for second order elliptic equations introduced by Raviart

(*) Manuscrit reçu le 11 septembre 1979

( $\left.{ }^{1}\right)$ Department of Mathematıcs, Chalmers Unıversity of Technology, S-41296 Goteborg, Suède

R A I.R O Analyse numérıque/Numencal Analysıs, 0399-0516/1981/41/\$ 5.00

(C) Bordas-Dunod 
and Thomas [13] and prove some $L_{2}$ and maximum-norm error estimates for such approximations. Hereby we extend or give alternative proofs of results by Raviart and Thomas [13], Falk and Osborn [9], and Scholz [14]. In particular, we introduce second order elements with one curved edge which makes it possible to handle the case of a domain with smooth curved boundaries. Then in Section 2 the results of Section 1 are extended to the corresponding parabolic problems. We consider both the case of a nonhomogeneous of homogeneous equation with a smooth solution and the case of a homogeneous equation with initial data only in $L_{2}$. In both situations we show optimal order error estimates, in the latter case for $t$ bounded away from zero. In Sections 3 and 4 we carry out the same program for an analogous mixed method introduced in [12], applied to the stationary and evolutionary Stokes' equations.

\section{THE ELLIPTIC PROBLEM}

In this section we shall consider the model problem

$$
-\Delta u=f \text { in } \Omega, \quad u=0 \text { on } \Gamma,
$$

where $\Omega$ is a bounded domain in the plane, with boundary $\Gamma$. Introducing the gradient of $u$ as a new variable this problem can also be formulated

$$
-\operatorname{div} \sigma=f, \quad \sigma=\nabla u \text { in } \Omega, \quad u=0 \text { on } \Gamma .
$$

Defining the spaces

$$
V=L_{2}(\Omega) \quad \text { and } \quad H=\left\{\chi \in L_{2}(\Omega)^{2} ; \operatorname{div} \chi \in L_{2}(\Omega)\right\},
$$

we note that a solution $(u, \sigma) \in V \times H$ of (1.1) may be thought of as a solution to the variational problem

$$
\begin{array}{ll}
(\operatorname{div} \sigma, v)+(f, v)=0, & \forall v \in V, \\
(\sigma, \chi)+(u, \operatorname{div} \chi)=0, & \forall \chi \in H,
\end{array}
$$

where (., . ) denote the usual inner products in $L_{2}(\Omega)^{m}, m=1,2$. Note that the boundary condition $u=0$ is implicitely contained in $(1.2 b)$; using Green's formula (with $n$ the exterior normal to $\Gamma$ ),

$$
\int_{\Omega} u \operatorname{div} \chi d x=\int_{\Gamma} u \chi \cdot n d x-\int_{\Omega} \nabla u \cdot \chi d x,
$$

we obtain, formally, $\sigma=\nabla u$ in $\Omega$ and $u=0$ on $\Gamma$. 
With $V_{h}$ and $H_{h}$ certain finite dimensional subspaces of $V$ and $H$ we shall now consider the following discrete analogue of (1.2): find $\left(u_{h}, \sigma_{h}\right) \in V_{h} \times H_{h}$ such that

$$
\begin{array}{ll}
\left(\operatorname{div} \sigma_{h}, v_{h}\right)+\left(f, v_{h}\right)=0, & \forall v_{h} \in V_{h}, \\
\left(\sigma_{h}, \chi_{h}\right)+\left(u_{h}, \operatorname{div} \chi_{h}\right)=0, & \forall \chi_{h} \in H_{h} .
\end{array}
$$

More precisely, we shall use pairs of subspaces $V_{h}$ and $H_{h}$ introduced for this purpose by Raviart and Thomas [13] which we shall now proceed to describe.

We consider first the case of a polygonal domain $\Omega$ which for simplicity we take to be convex and let $\mathscr{T}_{h}=\{K\}$ be a quasiuniform regular triangulation of $\Omega$ by triangles of diameter at most $h$. Let $r$ be an integer $\geqq 1$ and set

$$
V_{h}=\left\{v \in V ;\left.\left.v\right|_{K} \in \mathscr{P}_{r-1}\right|_{K}\right\},
$$

where $\mathscr{P}_{j}$ denotes the set of polynomials of degree at most $j$. Notice that no continuity across interelement boundaries is require of the functions in $V_{h}$. In order to define $H_{h}$, let $\hat{K}$ be the reference triangle in the $\xi$-plane with vertices $(0,0),(1,0)$ and $(0,1)$ and let, with $r$ as above, $\hat{H}$ denote the space of functions $\hat{\chi}=\left(\hat{\chi}_{1}, \hat{\chi}_{2}\right) \in \mathscr{P}_{r}^{2}$ on $\hat{K}$ of the following form: for $r$ even

$$
\begin{aligned}
& \hat{\chi}_{1}=p_{r-1}(\xi)+\alpha_{0} \xi_{1}^{r}+\alpha_{1} \xi_{1}^{r-1} \xi_{2}+\ldots+\alpha_{r / 2} \xi_{1}^{r / 2} \xi_{2}^{r / 2}, \\
& \hat{\chi}_{2}=q_{r-1}(\xi)+\beta_{0} \xi_{2}^{r}+\beta_{1} \xi_{1} \xi_{2}^{r-1}+\ldots+\beta_{r / 2} \xi_{1}^{r / 2} \xi_{2}^{r / 2},
\end{aligned}
$$

with

$$
\sum_{j=0}^{r / 2}(-1)^{j} \alpha_{j}=\sum_{j=0}^{r / 2}(-1)^{j} \beta_{j}=0
$$

and for $r$ odd

$$
\begin{aligned}
& \hat{\chi}_{1}=p_{r-1}(\xi)+\alpha_{0} \xi_{1}^{r}+\alpha_{1} \xi_{1}^{r-1} \xi_{2}+\ldots+\alpha_{(r-1) / 2} \xi_{1}^{(r+1) / 2} \xi_{2}^{(r-1) / 2}, \\
& \hat{\chi}_{2}=q_{r-1}(\xi)+\beta_{0} \xi_{2}^{r}+\beta_{1} \xi_{1} \xi_{2}^{r-1}+\ldots+\beta_{(r-1) / 2} \xi_{1}^{(r-1) / 2} \xi_{2}^{(r+1) / 2},
\end{aligned}
$$

with

$$
\sum_{j=0}^{(r-1) / 2}(-1)^{j}\left(\alpha_{j}-\beta_{j}\right)=0
$$

vol. $15, \mathrm{n}^{\circ} 1,1981$ 
where $p_{r-1}, q_{r-1}$ denote arbitrary polynomials in $\mathscr{P}_{r-1}$. Let now for given $K \in \mathscr{T}_{h}, F_{K}$ be an affine mapping of $\hat{K}$ onto $K$,

$$
x=F_{K}(\xi)=B_{K} \xi+b_{K},
$$

where $B_{K}$ is a $2 \times 2$ matrix and $b_{K} \in R^{2}$ and set

$$
H_{r}(K)=\left\{\chi=\left(\operatorname{det} B_{K}\right)^{-1} B_{K} \hat{\chi} \circ F_{K}^{-1} \text { where } \hat{\chi} \in \hat{K}_{r}\right\},
$$

and finally

$$
H_{h}=\left\{\chi \in H ;\left.\chi\right|_{K} \in H_{r}(K), \forall K \in \mathscr{T}_{h}\right\} .
$$

It follows from these definitions that $\operatorname{dim} H_{r}(K)=r(r+2)$ and that the normal component $\chi \cdot n$ of $\chi$ reduces to a polynomial of degree $r-1$ on each edge $S$ of a triangle $K \in \mathscr{T}_{h}$. Recall that the condition $\chi \in H$ in the definition of $H_{h}$ requires $\operatorname{div} \chi \in L_{2}(\Omega)$ which in turn is equivalent to requiring $\chi \cdot n$ to be continuous across interelement boundaries. We also recall that $\chi \in H_{h}$ is uniquely determined by the following degrees of freedom:

(i) the values of $\chi \cdot n$ at $r$ points on each edge $S$ of $\mathscr{T}_{h}(3 r$ conditions for each $K)$;

(ii) the value of the moments $\int_{K} x^{\alpha} \chi d x$ for $|\alpha| \leqq r-2$ on each $K(r(r-1)$ conditions for each $K$ ).

In our analysis we shall need the following lemma. Here and below we denote by \|\|$_{s}$ the norm in $H^{s}(\Omega)$, with $s$ sometimes omitted when zero. For other spaces $X$ [for instance the Sobolev spaces $W_{p}^{s}(\Omega)$ ] we write $\|.\|_{X}$.

Lemma 1.1: There exists a linear operator $\Pi_{h}: H \rightarrow H_{h}$ such that

$$
\begin{gathered}
\left(\operatorname{div} \Pi_{h} \chi, v_{h}\right)=\left(\operatorname{div} \chi, v_{h}\right), \quad \forall v_{h} \in V_{h}, \quad \chi \in H, \\
\left\|\Pi_{h} \chi-\chi\right\| \leqq C h^{s}\|\chi\|_{s} \quad \text { for } \quad 1 \leqq s \leqq r, \\
\left\|\Pi_{h} \chi\right\| \leqq C\|\chi\|_{W_{1}^{1}(\Omega)} .
\end{gathered}
$$

The operator $\Pi_{h}$ may be defined by requiring that:

(i) $\int_{S} s^{j}\left(\Pi_{h} \chi-\chi\right) \cdot n d s=0 \quad$ for $\quad j \leqq r-1 \quad$ for each edge $S$ of $\mathscr{T}_{h}$;

(ii) $\int_{K} x^{\alpha}\left(\Pi_{h} \chi-\chi\right) d x=0 \quad$ for $\quad|\alpha| \leqq r-2$ for each $K \in \mathscr{T}_{h}$. 
The condition (1.4a) follows by Green's formula applied to each $K,(1.4 b)$ by the Bramble-Hilbert lemma and the boundedness via a trace theorem of the interpolation operator on the reference triangle as an operator $H^{s}(\hat{K}) \rightarrow L_{2}(\hat{K})$, and $(1.4 c)$ similarly by its boundedness from $W_{1}^{1}(\hat{K})$ to $L_{2}(\hat{K})$.

We shall also use the orthogonal $L_{2}$ projection $P_{h}: V \rightarrow V_{h}$ for which as is well known,

$$
\left\|P_{h} v-v\right\|_{L_{p}(\Omega)} \leqq C h^{s}\|v\|_{W_{p}^{s}(\Omega)} \quad \text { for } \quad 0 \leqq s \leqq r .
$$

It follows easily from this that

$$
\left\|P_{h} v-v\right\|_{L_{\infty}(\Omega)} \leqq C h^{s}\left(\log \frac{1}{h}\right)^{1 / 2}\|v\|_{s+1} \quad \text { for } \quad 0 \leqq s \leqq r .
$$

In fact, using a bounded extension operator $E: H^{s+1}(\Omega) \rightarrow H^{s+1}\left(R^{2}\right)$, setting $\tilde{v}=E v$ and defining $v_{0}=\left(\hat{\tilde{v}} \chi_{h}\right)^{\vee}$ where $\chi_{h}$ is the characteristic function of the set $\left\{\xi ;|\xi| \leqq h^{-1}\right\}$ and $\wedge$ and $\vee$ denote Fourier transformation and its inverse we have, by $(1.5 a)$,

$$
\left\|P_{h} v-v\right\|_{L_{x}(\Omega)} \leqq C h^{s}\left\|v_{0}\right\|_{W_{x}^{s}\left(R^{2}\right)}+C\left\|\tilde{v}-v_{0}\right\|_{L_{x}\left(R^{2}\right)},
$$

from which $(1.5 b)$ follows since simple computations yield

$$
\begin{aligned}
&\left\|\tilde{v}-v_{0}\right\|_{L_{\infty}\left(R^{2}\right)}=\left\|\left(\tilde{v}_{0}\left(1-\chi_{h}\right)\right)^{\vee}\right\|_{L_{\infty}\left(R^{2}\right)} \leqq C\left\|\tilde{v}_{0}\left(1-\chi_{h}\right)\right\|_{L_{1}} \\
& \leqq C h^{s}\|\tilde{v}\|_{s+1} \leqq C h^{s}\|v\|_{s+1},
\end{aligned}
$$

and similarly

$$
\left\|v_{0}\right\|_{W_{\alpha}^{s}\left(R^{2}\right)} \leqq C\left\|\sum_{|\alpha| \leqq s} \xi^{\alpha} \hat{\tilde{v}} \chi_{h}\right\|_{L_{1}\left(R^{2}\right)} \leqq C\left(\log \frac{1}{h}\right)^{1 / 2}\|v\|_{s+1} .
$$

Notice that $\chi_{h} \in H_{h}$ implies $\operatorname{div} \chi_{h} \in V_{h}$ and that $(1.4 a)$ shows that $\operatorname{div} \Pi_{h} \chi=P_{h} \operatorname{div} \chi$ so that in particular

$$
\left\|\operatorname{div}\left(\Pi_{h} \chi-\chi\right)\right\| \leqq C h^{s}\|\operatorname{div} \chi\|_{s} \quad \text { for } \quad 0 \leqq s \leqq r .
$$

Recall also that by the quasi-uniformity of $\mathscr{T}_{h}$ we have the inverse estimate

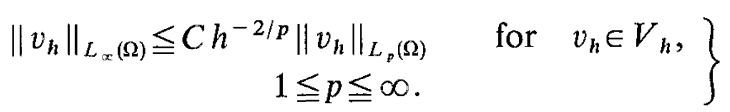


We now return to the elliptic problem (1.2) and its discrete counterpart (1.3). Existence, uniqueness and error estimates for this problem were discussed in Raviart and Thomas [13] and Thomas [16] using the general theory of Brezzi [6] and somewhat more precise estimates have been derived in Falk and Osborn [9] and for the maximum-norm in Scholtz [14]. We present here a simple error analysis which shows $L_{2}$-error estimates for $u_{h}$ and $\sigma_{h}$ under minimal smoothness assumptions on $u$, and in addition a maximum-norm error estimate for $u_{h}$. The analysis of the error in $u_{h}$ is based on the following two lemmas which are proved by the analogue in the present context of the standard duality argument.

LeMmA 1.2: Let $1 \leqq p \leqq \infty$. There are constants $C_{p}$ and $C$ such that if $w_{h} \in V_{h}$ and $\omega \in L^{2}(\Omega)^{2}$ satisfy

$$
\left(\omega, \chi_{h}\right)+\left(w_{h}, \operatorname{div} \chi_{h}\right)=0, \quad \forall \chi_{h} \in H_{h},
$$

then

$$
\left\|w_{h}\right\|_{L_{p}(\Omega)} \leqq C_{p}\|\omega\| \quad \text { if } \quad p<\infty
$$

and

$$
\left\|w_{h}\right\|_{L_{\infty}(\Omega)} \leqq C \log \frac{1}{h}\|\omega\|
$$

Proof: Let $p<\infty$ and let $\psi \in L_{q}(\Omega)$ where $p^{-1}+q^{-1}=1$. Let $\widetilde{\Omega} \supset \Omega$ be a domain with smooth boundary and extend $\psi$ by zero in $\widetilde{\Omega} \backslash \Omega$. Let $\varphi$ be the solution of

$$
\Delta \varphi=\psi \quad \text { in } \widetilde{\Omega}, \quad \varphi=0 \text { on } \partial \widetilde{\Omega},
$$

and recall the elliptic regularity estimate (cf. Agmon, Douglis and Nirenberg [1]):

$$
\|\varphi\|_{W_{q}^{2}(\tilde{\Omega})} \leqq C_{q}\|\psi\|_{L_{q}(\tilde{\Omega})}=C_{q}\|\psi\|_{L_{q}(\Omega)} .
$$

We have then, using $(1.4 a),(1.4 c),(1.8)$ and obvious estimates

$$
\begin{aligned}
\left(w_{h}, \psi\right)=\left(w_{h}, \operatorname{div} \nabla \varphi\right) & =\left(w_{h}, \operatorname{div} \Pi_{h} \nabla \varphi\right)=-\left(\omega, \Pi_{h} \nabla \varphi\right) \\
\leqq\|\omega\| \cdot\left\|\Pi_{h} \nabla \varphi\right\| & \leqq C\|\omega\| \cdot\|\nabla \varphi\|_{W_{q}^{1}(\Omega)} \\
& \leqq C\|\omega\| \cdot\|\varphi\|_{W_{q}^{2}(\tilde{\Omega})} \leqq C C_{q}\|\omega\| \cdot\|\psi\|_{L_{q}(\Omega)},
\end{aligned}
$$

which proves (1.9). In order to show (1.10), note that for $q$ close to 1 (or $p$ large) the constant $C_{q}$ in (1.11) satisfies

$$
C_{q} \leqq \frac{C}{q-1} \leqq C p .
$$


This follows by tracing the dependence of $C_{q}$ upon $q$ in the proof of (1.11) in [1] to the Calderon-Zygmund lemma [7] in which such an estimate is valid. Using the inverse assumption (1.7) we therefore have with $C$ independent of $p$,

$$
\left\|w_{h}\right\|_{L_{\infty}(\Omega)} \leqq C h^{-2 / p}\left\|w_{h}\right\|_{L_{p}(\Omega)} \leqq C p h^{-2 / p}\|\omega\| .
$$

The conclusion now follows by choosing $p=\log h^{-1}$.

Lemma 1.3: There is a constant $C$ such that if $\left(w_{h}, \omega\right) \in V_{h} \times H$ satisfy

$$
\begin{gathered}
\left(\omega, \chi_{h}\right)+\left(w_{h}, \operatorname{div} \chi_{h}\right)=0, \quad \forall \chi_{h} \in H_{h}, \\
\left(\operatorname{div} \omega, v_{h}\right)=0, \quad \forall v_{h} \in V_{h},
\end{gathered}
$$

then

$$
\left\|w_{h}\right\| \leqq C\left\{h\|\omega\|+h^{2}\|\operatorname{div} \omega\|\right\} .
$$

Proof: Let $\psi \in L_{2}(\Omega)$ and let $\varphi \in H^{2}(\Omega)$ be the solution of

$$
\Delta \varphi=\psi \quad \text { in } \Omega, \quad \varphi=0 \text { on } \Gamma,
$$

so that, recalling that $\Omega$ is convex,

$$
\|\varphi\|_{2} \leqq C\|\psi\| \text {. }
$$

We have then, using (1.4a) and (1.12a),

$$
\begin{aligned}
\left(w_{h}, \psi\right)=\left(w_{h}, \operatorname{div} \nabla \varphi\right) & =\left(w_{h}, \operatorname{div} \Pi_{h} \nabla \varphi\right) \\
& =-\left(\omega, \Pi_{h} \nabla \varphi\right)=-\left(\omega, \Pi_{h} \nabla \varphi-\nabla \varphi\right)-(\omega, \nabla \varphi)=I_{1}+I_{2} .
\end{aligned}
$$

Here

$$
\left|I_{1}\right| \leqq\|\omega\| .\left\|\Pi_{h} \nabla \varphi-\nabla \varphi\right\| \leqq C h\|\omega\| .\|\nabla \varphi\|_{1} \leqq C h\|\omega\| .\|\psi\|,
$$

and using Green's formula and $(1.12 b)$,

$$
I_{2}=(\operatorname{div} \omega, \varphi)=\left(\operatorname{div} \omega, \varphi-P_{h} \varphi\right),
$$

so that

$$
\left|I_{2}\right| \leqq\|\operatorname{div} \omega\| .\left\|\varphi-P_{h} \varphi\right\| \leqq C h^{2}\|\varphi\|_{2}\|\operatorname{div} \omega\| \leqq C h^{2}\|\psi\| .\|\operatorname{div} \omega\| .
$$

Altogether

$$
\left|\left(w_{h}, \psi\right)\right| \leqq C\left(h\|\omega\|+h^{2}\|\operatorname{div} \omega\|\right)\|\psi\|,
$$

which proves the lemma.

We can now state and prove the following: 
THEOREM 1.1: The discrete problem (1.3) has exactly one solution $\left(u_{h}, \sigma_{h}\right) \in V_{h} \times H_{h}$. With $(u, \sigma)$ the solution of $(1.1)$ we have

$$
\begin{gathered}
\left\|u_{h}-u\right\| \leqq C h^{s}\|u\|_{s} \quad \text { for } \quad 2 \leqq s \leqq r \\
\left\|\sigma_{h}-\sigma\right\| \leqq C h^{s}\|u\|_{s+1}
\end{gathered}
$$

and

$$
\left\|u_{h}-u\right\|_{L_{\infty}(\Omega)} \leqq C h^{s} \log \frac{1}{h}\|u\|_{s+1} \quad \text { for } \quad 1 \leqq s \leqq r .
$$

Proof: In order to show existence it is clearly sufficient to prove uniqueness. Thus let $f=0$. We obtain by setting $v_{h}=u_{h}, \chi_{h}=\sigma_{h}$ in (1.3),

$$
\left\|\sigma_{h}\right\|^{2}=-\left(u_{h}, \operatorname{div} \sigma_{h}\right)=0
$$

so that $\sigma_{h}=0$. By lemma 1.2 we conclude at once that $u_{h}=0$ which completes the proof.

In the error analysis we shall begin with the estimate for $\sigma_{h}-\sigma$. We first show that:

$$
\left\|\sigma_{h}-\sigma\right\| \leqq\left\|\Pi_{h} \sigma-\sigma\right\|
$$

In fact, by $(1.2 a),(1.4 a)$ and the discrete equation $(1.3 a)$ we have

$$
\left(\operatorname{div}\left(\Pi_{h} \sigma-\sigma_{h}\right), v_{h}\right)=0, \quad \forall v_{h} \in V_{h},
$$

so that since $\operatorname{div}\left(\Pi_{h} \sigma-\sigma_{h}\right) \in V_{h}, \operatorname{div}\left(\Pi_{h} \sigma-\sigma_{h}\right)=0$. But by $(1.2 b)$ and $(1.3 b)$ we have

$$
\left(\sigma_{h}-\sigma, \chi_{h}\right)+\left(u_{h}-u, \operatorname{div} \chi_{h}\right)=0, \quad \forall \chi_{h} \in H_{h},
$$

so that, in particular, with $\chi_{h}=\Pi_{h} \sigma-\sigma_{h}$,

$$
\left(\sigma_{h}-\sigma, \sigma_{h}-\Pi_{h} \sigma\right)=0,
$$

which shows (1.14). The desired estimate for $\sigma_{h}-\sigma$ now follows by $(1.4 b)$.

We now turn to the maximum-norm estimate. Since (1.16) may be written

$$
\left(\sigma_{h}-\sigma, \chi_{h}\right)+\left(u_{h}-P_{h} u, \operatorname{div} \chi_{h}\right)=0, \quad \forall \chi_{h} \in H_{h},
$$

we conclude by Lemma 1.2 and the above estimate for $\sigma_{h}-\sigma$,

$$
\left\|u_{h}-P_{h} u\right\|_{L_{\alpha}} \leqq C \log \frac{1}{h}\left\|\sigma_{h}-\sigma\right\| \leqq C h^{s} \log \frac{1}{h}\|u\|_{s+1} .
$$

By $(1.5 b)$ this shows $(1.13)$. 
It remains to show the $L_{2}$ error estimate. For this purpose, notice that the error equations may be written

$$
\begin{gathered}
\left(\sigma_{h}-\sigma, \chi_{h}\right)+\left(u_{h}-P_{h} u, \operatorname{div} \chi_{h}\right)=0, \quad \forall \chi_{h} \in H_{h}, \\
\left(\operatorname{div}\left(\sigma_{h}-\sigma\right), v_{h}\right)=0, \quad \forall v_{h} \in V_{h},
\end{gathered}
$$

so that we may apply Lemma 1.3 to obtain

$$
\left\|u_{h}-P_{h} u\right\| \leqq C\left\{h\left\|\sigma_{h}-\sigma\right\|+h^{2}\left\|\operatorname{div}\left(\sigma_{h}-\sigma\right)\right\|\right\},
$$

and hence in view of $(1.4 b)$ and (1.6),

$$
\left\|u_{h}-P_{h} u\right\| \leqq C\left\{h^{s}\|u\|_{s}+h^{s}\|\operatorname{div} \sigma\|_{s-2}\right\} \leqq C h^{s}\|u\|_{s}
$$

for $2 \leqq s \leqq r$. Together with the obvious estimate for $u-P_{h} u$ this completes the proof of the $L_{2}$ estimate and thus the proof of the theorem.

In order to be able to conclude maximal order rates from Theorem 1.1, we need to know that the solution is appropriately smooth. For polygonal domains this is in general not the case so the conclusions are in practice relatively weak. We shall therefore now discuss the elliptic problems (1.2) and (1.3) in a convex domain $\Omega$ with smooth boundary $\Gamma$. We shall consider extensions to $\Omega$ of the elements described above in the case $r=2$ and carry out the error analysis for this situation. For a corresponding analysis of the case $r=3$, see [10].

Let $\mathscr{T}_{h}=\{K\}$ be a quasi-uniform regular triangulation of $\Omega$ such that the polygonal domain $\Omega_{h}$ determined by $U K$ has its vertices on $\Gamma$. For a boundary triangle $K$ let $\widetilde{K}$ be the obvious extension to a triangle with one curved edge, and set for convenience $\widetilde{K}=K$ for other $K$. We define

$$
V_{h}=\left\{v \in V ;\left.\left.v\right|_{K} \in \mathscr{P}_{1}\right|_{K}, v=0 \text { in } \Omega \backslash \Omega_{h}\right\},
$$

and

$$
H_{h}=\left\{\chi \in H ;\left.\left.\chi\right|_{\tilde{K}} \in \mathscr{P}_{2}^{2}\right|_{\tilde{K}},\left.\chi\right|_{K} \in H_{2}(K)\right\}
$$

Thus, $V_{h}$ consists of the piecewise linear functions on $\Omega_{h}$, without continuity requirements across interelement boundaries, extended by zero, and $H_{h}$ of the corresponding functions on $\Omega_{h}$ which are simply extended to $\Omega$ by using the same polynomial on $\tilde{K}$ as on $K$.

We shall need the fact that the conclusions of Lemma 1.1 are valid after this modification. In fact, let $\Pi_{h}$ be defined as above locally on each triangle $K$, which now defines $\Pi_{h} \chi$ for $\chi \in H$ on all of $\Omega$ by the extension from $K$ to $\widetilde{K}$ in the definition of $H_{h}$. Clearly $(1.4 a)$ still holds since it holds on each $K$ and $v_{h}$ 
vanishes outside $\Omega_{h}$. Further, similarly to the case of straight triangles we have for boundary triangles with possible curved edges

$$
\left\|\Pi_{h} \chi-\chi\right\|_{L_{2}(\tilde{K})} \leqq C h^{s}\|\chi\|_{H^{s}(\tilde{K})} \quad \text { for } \quad 1 \leqq s \leqq 2,
$$

so that $(1.4 b)$ is valid as before. Since it is easy to see that

$$
\left\|\chi_{h}\right\|_{L_{2}(\tilde{K})} \leqq C\left\|\chi_{h}\right\|_{L_{2}(K)}, \quad \forall K \in \mathscr{T}_{h},
$$

we conclude that $(1.4 c)$ still holds. We also note that similarly

$$
\left\|\operatorname{div} \Pi_{h} \chi\right\| \leqq C\left\|\operatorname{div} \Pi_{h} \chi\right\|_{L_{2}\left(\Omega_{h}\right)}=C\left\|P_{h} \operatorname{div} \chi\right\| \leqq C\|\operatorname{div} \chi\| .
$$

Notice that in the present situation $\chi_{h} \in H_{h}$ does not imply div $\chi_{h} \in V_{h}$ but instead we have $\operatorname{div} \chi_{h} \in \widetilde{V}_{h}$ where

$$
\widetilde{V}_{h}=\left\{v \in V ;\left.v\right|_{K} \text { and }\left.\left.v\right|_{\tilde{K}} \in \mathscr{P}_{1}\right|_{\tilde{K}}\right\} .
$$

In our error analysis below it will be convenient to use the following associated modification of the $L_{2}$-projection $P_{h}$ used above for polygonal domains.

Lemma 1.4: Let $\widetilde{P}_{h}: V \rightarrow V_{h}$ be defined by

$$
\left(\tilde{P}_{h} v, \tilde{v}_{h}\right)=\left(v, \tilde{v}_{h}\right), \quad \forall \tilde{v}_{h} \in \tilde{V}_{h} .
$$

Then

and

$$
\left.\left\|\widetilde{P}_{h} v-v\right\|_{L_{p}(\Omega)} \leqq C h^{2}\|v\|_{W_{p}^{2}(\Omega)} \quad \begin{array}{r}
\text { for } 2 \leqq p \leqq \infty \\
\text { if } v=0 \text { on } \Gamma,
\end{array}\right\}
$$

$$
\left\|\widetilde{P}_{h} v-v\right\|_{L_{x}(\Omega)} \leqq C h^{2}\left(\log \frac{1}{h}\right)^{1 / 2}\|v\|_{3}, \quad \text { if } \quad v=0 \quad \text { on } \Gamma .
$$

Proof: Note first that (1.18) defines $\widetilde{P}_{h}$ uniquely. We shall compare $\widetilde{P}_{h}$ to the $L_{2}$ projection $P_{h}: V \rightarrow V_{h}$ which satisfies

$$
\left(P_{h} v, v_{h}\right)=\left(v, v_{h}\right), \quad \forall v_{h} \in V_{h},
$$

and for which as is well known

$$
\left\|P_{h} v-v\right\|_{L_{p}(\Omega)} \leqq C h^{2}\|v\|_{W_{p}^{2}(\Omega)} .
$$

We obtain for $v_{h} \in V_{h}$ with $\tilde{v}_{h}$ the associated element in $\tilde{V}_{h}$ defined by $\tilde{v}_{h \mid K}=v_{h \mid K}$, $\forall K \in \mathscr{T}_{h}$, that

$$
\left(\tilde{P}_{h} v-P_{h} v, v_{h}\right)=\left(\tilde{P}_{h} v-P_{h} v, \tilde{v}_{h}\right)=\left(v, \tilde{v}_{h}\right)_{L_{2}\left(\Omega \backslash \Omega_{h}\right)} \leqq\|v\|_{L_{2}\left(\Omega \backslash \Omega_{h}\right)}\left\|\tilde{v}_{h}\right\|_{L_{2}\left(\Omega \backslash \Omega_{h}\right)} .
$$


Notice now that for each $K$,

$$
\left\|\tilde{v}_{h}\right\|_{L_{2}(\tilde{K} \backslash K)} \leqq C\left\|\tilde{v}_{h}\right\|_{L_{2}(K)}
$$

and hence

$$
\left\|\tilde{v}_{h}\right\|_{L_{2}\left(\Omega \backslash \Omega_{h}\right)} \leqq C\left\|\tilde{v}_{h}\right\|_{L_{2}\left(\Omega_{h}\right)}=C\left\|v_{h}\right\|
$$

This shows

$$
\left\|\tilde{P}_{h} v-P_{h} v\right\| \leqq C\|v\|_{L_{2}\left(\Omega \backslash \Omega_{h}\right)} .
$$

In view of the inverse estimate (1.7), this yields with $C$ independent of $p$,

$$
\left\|\widetilde{P}_{h} v-P_{h} v\right\|_{L_{p}(\Omega)} \leqq C h^{-(1-(2 / p))}\|v\|_{L_{2}\left(\Omega \backslash \Omega_{h}\right)} \leqq C\|v\|_{L_{p}\left(\Omega \backslash \Omega_{h}\right)},
$$

and since

$$
\|v\|_{L_{p}\left(\Omega \backslash \Omega_{h}\right)} \leqq C h^{2}\|v\|_{W_{p}^{1}\left(\Omega \backslash \Omega_{h}\right)} \text { when } v=0 \text { on } \Gamma \text {, }
$$

we conclude for such $v$,

$$
\left\|\widetilde{P}_{h} v-P_{h} v\right\|_{L_{p}(\Omega)} \leqq C h^{2}\|v\|_{W_{p}^{1}(\Omega)} .
$$

Together with (1.21) this completes the proof of (1.19).

In the same way as for the case of $\Omega$ polygonal we have

$$
\left\|P_{h} v-v\right\|_{L_{x}(\Omega)} \leqq C h^{2}\left(\log \frac{1}{h}\right)^{1 / 2}\|v\|_{3},
$$

which implies (1.20) since by (1.22),

$$
\left\|\widetilde{P}_{h} v-P_{h} v\right\|_{L_{\alpha}(\Omega)} \leqq C h^{2}\|v\|_{3} .
$$

This completes the proof of the lemma.

We may now immadiately state and prove:

THEOREM 1.2: Under the present assumptions about $\Omega, V_{h}$ and $H_{h}$, the discrete problem (1.3) has a unique solution $\left(u_{n}, \sigma_{h}\right)$. If $(u, \sigma)$ denotes the solution of (1.2), we have

$$
\begin{gathered}
\left\|u_{h}-u\right\| \leqq C h^{2}\|u\|_{2}, \\
\left\|\sigma_{h}-\sigma\right\| \leqq C h^{2}\|u\|_{3},
\end{gathered}
$$

and

$$
\left\|u_{h}-u\right\|_{L,(\Omega)} \leqq C h^{2} \log \frac{1}{h}\|u\|_{3}
$$

vol. $15, \mathrm{n}^{\circ} 1,1981$ 
Proof: We first note that in view of the properties of the operator $\Pi_{h}$ as described in Lemma 1.1, the proof of Lemma 1.2 remains unchanged (in fact, this time we may choose $\widetilde{\Omega}=\Omega$ ). As in the proof of Theorem 1.1 this shows the uniqueness and hence the existence of a solution $\left(u_{h}, \sigma_{h}\right)$ of (1.3). In order to show the error estimates, we follow the lines of the proof of Theorem 1.1. We first notice that (1.15) again implies $\operatorname{div}\left(\Pi_{h} \sigma-\sigma_{h}\right)=0$ on $\Omega_{h}$ and hence on $\Omega$ so that

$$
\left\|\sigma_{h}-\sigma\right\| \leqq\left\|\Pi_{h} \sigma-\sigma\right\| \leqq C h^{s}\|\sigma\|_{s} \leqq C h^{s}\|u\|_{s+1}, \quad 1 \leqq s \leqq 2 .
$$

This time we have instead of (1.16),

$$
\left(\sigma_{h}-\sigma, \chi_{h}\right)+\left(\mathrm{u}_{h}-\widetilde{P}_{h} u, \operatorname{div} \chi_{h}\right)=0, \quad \forall \chi \in H_{h},
$$

so that by the modification of lemma 1.2 ,

$$
\left\|u_{h}-\widetilde{P}_{h} u\right\|_{L,(\Omega)} \leqq C \log \frac{1}{h}\left\|\sigma_{h}-\sigma\right\| \leqq C h^{2} \log \frac{1}{h}\|u\|_{3} .
$$

Recalling (1.20) this completes the proof of the maximum norm estimate. Finally, applying Lemma 1.3 (the proof of which remains unchanged except that $P_{h}$ is replaced by $\left.\widetilde{P}_{h}\right),(1.17)$ and Lemma 1.1 , we have

$$
\begin{aligned}
\left\|u_{h}-\widetilde{P}_{h} u\right\| \leqq C\left\{h\left\|\sigma_{h}-\sigma\right\|+h^{2} \| \operatorname{div}\right. & \left.\left(\sigma_{h}-\sigma\right) \|\right\} \\
& \leqq C h^{2}\left(\|\sigma\|_{1}+\|\operatorname{div} \sigma\|\right) \leqq C h^{2}\|u\|_{2} .
\end{aligned}
$$

In view of (1.19) this completes the proof.

For given $f \in L_{z}(\Omega)$ we may think of the solution $\left(u_{h}, \sigma_{h}\right)$ of $(1,3)$ as the result of a pair of operators $\left(T_{h}, S_{h}\right): L_{2}(\Omega) \rightarrow V_{h} \times H_{h}$ defined by $T_{h} f=u_{h}, S_{h} f=\sigma_{h}$. Setting similarly for the exact solution $u=\mathrm{T} f$ with $T: L_{2}(\Omega) \rightarrow H^{2}(\Omega)$ we prove for later use the following lemma. The properties stated are used in e.g. [3], [4] and [2] to analyze discretizations of eigenvalue problems and parabolic problems, respectively.

LemMA 1.5: The operator $T_{h}: L_{2}(\Omega) \rightarrow V_{h}$ is positive semidefinite on $L_{2}(\Omega)$ and positive definite on $V_{h}$ considered as an inner product space with inner product (.,.). Further

$$
\left\|T_{h} f-T f\right\| \leqq C h^{s}\|f\|_{s-2} \quad \text { for } \quad 2 \leqq s \leqq r .
$$

Proof: The discrete problem may be written

$$
\begin{array}{cc}
\left(\operatorname{div} S_{h} f, v_{h}\right)=-\left(f, v_{h}\right), & \forall v_{h} \in V_{h}, \\
\left(S_{h} f, \chi_{h}\right)+\left(T_{h} f, \operatorname{div} \chi_{h}\right)=0, & \forall \chi_{h} \in H_{h} .
\end{array}
$$


Now by these relations

$$
\left(f_{1}, T_{h} f_{2}\right)=-\left(\operatorname{div} S_{h} f_{1}, T_{h} f_{2}\right)=\left(S_{h} f_{1}, S_{h} f_{2}\right), \quad \forall f_{1}, f_{2} \in L_{2}(\Omega),
$$

which shows that $T_{h}$ is selfadjoint and positive semidefinite on $L_{2}(\Omega)$. Let now $f_{h} \in V_{h}$ be such that $T_{h} f_{h}=0$. Then $S_{h} f_{h}=0$ and hence

$$
\left\|f_{h}\right\|^{2}=-\left(f_{h}, \operatorname{div} S_{h} f_{h}\right)=0,
$$

so that $f_{h}=0$ which shows that $T_{h}$ is positive definite on $V_{h}$. The estimate (1.24) now follows at once by Theorems 1.1 and 1.2 depending on the case considered, since

$$
\left\|T_{h} f-T f\right\|=\left\|u_{h}-u\right\| \leqq C h^{s}\|u\|_{s} \leqq C h^{s}\|f\|_{s-2} .
$$

This completes the proof of the lemma.

\section{A PARABOLIC PROBLEM}

Let us now consider, with $\Omega$ and $\Gamma$ as above, the initial-boundary value problem

$$
\begin{gathered}
u_{t}-\Delta u=f \text { in } \Omega \times R_{+}, \\
u=0 \text { on } \Gamma \times R_{+}, \\
u(., 0)=g \text { in } \Omega,
\end{gathered}
$$

where $u_{t}=\partial u / \partial t$ and $R_{+}=(0, \infty)$. Introducing again $\sigma=\nabla u$ this may be written in variational form: find $(u, \sigma): R_{+} \rightarrow V \times H$ such that

$$
\begin{gathered}
\left(u_{t}, v\right)-(\operatorname{div} \sigma, v)=(f, v), \quad \forall v \in V, \quad t \in R_{+}, \\
(\sigma, \chi)+(u, \operatorname{div} \chi)=0, \quad \forall \chi \in H, \quad t \in R_{+}, \\
u(0)=g,
\end{gathered}
$$

where $V$ and $H$ are as in Section 1. With $V_{h} \subset V$ and $H_{h} \subset H$ as before it is natural to consider its semidiscrete analogue: Find $\left(u_{h}, \sigma_{h}\right): R_{+} \rightarrow V_{h} \times H_{h}$ such that

$$
\begin{gathered}
\left.\left(u_{h, t}, v_{h}\right)-\operatorname{div} \sigma_{h}, v_{h}\right)=\left(f, v_{h}\right), \quad \forall v_{h} \in V_{h}, \quad t \in R_{+}, \\
\left(\sigma_{h}, \chi_{h}\right)+\left(u_{h}, \operatorname{div} \chi_{h}\right)=0, \quad \forall \chi_{h} \in H_{h}, \quad t \in R_{+}, \\
u_{h}(0)=g_{h},
\end{gathered}
$$

where $g_{h}$ is some approximation in $V_{h}$ of $g$. Note that $u_{h}(0)$ determines $\sigma_{h}(0)$ by the second discrete equation $(2.2 \mathrm{~b})$. 
Introducing bases in $V_{h}$ and $H_{h}$ this problem may be written in matrix form as

$$
\begin{aligned}
& A U_{t}-B \Sigma=F, \\
& B^{T} U+D \Sigma=0,
\end{aligned}
$$

with $U(0)$ given, where $A$ and $D$ are positive definite. After elimination of $\Sigma$, this may be thought of as a linear system of ordinary differential equations in $U$ with a positive definite coefficient of $U_{t}$ and therefore this system has a unique solution for $t \geqq 0$.

Recalling the definition of the operator $T_{h}$ above, (2.2) can be written

$$
T_{h} u_{h, t}+u_{h}=T_{h} f \quad \text { for } t \geqq 0, \quad u_{h}(0)=g_{h} .
$$

Since $T_{h}$ is positive definite on $V_{h}$ this again shows that (2.2) has a unique solution $u_{h}(t) \in V_{h}$ for $t \geqq 0$. Once $u_{h}$ has been determined, $\sigma_{h}$ may be found from $(2.2 b)$. The above representation of the semidiscrete problem, with $\sigma_{h}$ eliminated, and the corresponding form of the continuous problem,

$$
T u_{t}+u=T f \quad \text { for } \quad t \geqq 0, \quad u(0)=g,
$$

with $T$ the inverse of $-\Delta$ can be used to deduce error estimates for $u_{h}(c f$. [4]). This approach will be taken in theorem 2.3, which deals with the homogeneous equation $(f=0)$. Furthermore, this representation of the semi-discrete problem could be used to formulate fully discrete analogues of (2.2) based on rational approximations of the exponential ( $c f$. [2] in the case $f=0$ ).

Our next purpose is to derive error estimates for both $u_{h}$ and $\sigma_{h}$ in the general case of the nonhomogeneous problem (2.1) and its semidiscrete analogue (2.2). In doing so we shall treat simultaneously the situation covered in the elliptic case by Theorem 1.1 when $\Omega$ is polygonal and the order of accuracy $r$ is arbitrary, and by Theorem 1.2 when $\Omega$ is smooth and $r=2$. The analysis by the energy method uses an analogue in the present context of the "elliptic projection" of the exact solution, which we define here to be $\left(\tilde{u}_{h}, \tilde{\sigma}_{h}\right)=\left(-T_{h} \Delta u,-S_{h} \Delta u\right)$, the solution of the discrete stationary problem (1.3) with $f=-\operatorname{div} \sigma=-\Delta u$. We shall use for discrete initial data $-T_{h} \Delta g$ which we may then think of as an elliptic projection of $g$ into $V_{h}$.

THEOREM 2.1: Let $u_{h}(0)=-T_{h} \Delta g$ be the elliptic projection of $g$. Then for $t \geqq 0$, $2 \leqq s \leqq r$ (with $s=r=2$ in the case that $\Gamma$ is smooth).

Further

$$
\left\|u_{h}(t)-u(t)\right\| \leqq C h^{s}\left\{\|u(t)\|_{s}+\int_{0}^{t}\left\|u_{t}\right\|_{s} d \tau\right\} .
$$

$$
\left\|\sigma_{h}(t)-\sigma(t)\right\| \leqq C h^{s}\left\{\|u(t)\|_{s+1}+\left(\int_{0}^{t}\left\|u_{t}\right\|_{s}^{2} d \tau\right)^{1 / 2}\right\} \text {, }
$$


and

$$
\left\|u_{h}(t)-u(t)\right\|_{L,(\Omega)} \leqq C h^{s} \log \frac{1}{h}\left\{\|u(t)\|_{s+1}+\left(\int_{0}^{t}\left\|u_{t}\right\|_{s}^{2} d \tau\right)^{1 / 2}\right\} .
$$

Proof: Let $\left(\tilde{u}_{h}, \tilde{\sigma}_{h}\right)$ be the elliptic projection of $(u, \sigma)$, and set

$$
e_{h}=u_{h}-\tilde{u}_{h}, \quad \varepsilon_{h}=\sigma_{h}-\tilde{\sigma}_{h}, \quad \rho=u-\tilde{u}_{h} .
$$

We may then write the error equations in the from

$$
\begin{gathered}
\left(e_{h, t}, v_{h}\right)-\left(\operatorname{div} \varepsilon_{h}, v_{h}\right)=\left(\rho_{t}, v_{h}\right), \quad \forall v_{h} \in V_{h}, \\
\left(\varepsilon_{h}, \chi_{h}\right)+\left(e_{h}, \operatorname{div} \chi_{h}\right)=0, \quad \forall \chi_{h} \in H_{h} .
\end{gathered}
$$

Notice that $e_{h}(0)=0$ and that hence also $\varepsilon_{h}(0)=0$ or $\sigma_{h}(0)=\tilde{\sigma}_{h}(0)$. Recall also from Theorems 1.1 and 1.2 that for $2 \leqq s \leqq r$,

$$
\begin{gathered}
\|\rho(t)\|=\left\|u(t)-\tilde{u}_{h}(t)\right\| \leqq C h^{s}\|u(t)\|_{s} \\
\left\|\sigma(t)-\tilde{\sigma}_{h}(t)\right\| \leqq C h^{s}\|u(t)\|_{s+1}
\end{gathered}
$$

and

$$
\|\rho(t)\|_{L_{\infty}(\Omega)} \leqq C h^{s} \log \frac{1}{h}\|u(t)\|_{s+1} .
$$

Now taking $v_{h}=e_{h}, \chi_{h}=\varepsilon_{h}$ in (2.6) and adding, we obtain

$$
\frac{1}{2} \frac{d}{d t}\left\|e_{h}\right\|^{2}+\left\|\varepsilon_{h}\right\|^{2}=\left(\rho_{t}, e_{h}\right)
$$

and hence

$$
\left\|e_{h}(t)\right\| \leqq \int_{0}^{t}\left\|\rho_{t}\right\| d \tau \leqq C h^{s} \int_{0}^{t}\left\|u_{t}\right\|_{s} d \tau
$$

Since

$$
\left\|u_{h}(t)-u(t)\right\| \leqq\|\rho(t)\|+\left\|e_{h}(t)\right\|,
$$

(2.3) follows from (2.7).

In order to show the estimate (2.4) we differentiate $(2.6 \mathrm{~b})$ with respect to $t$, set $v_{h}=e_{h, t}, \chi_{h}=\varepsilon_{h}$, and add to obtain this time

$$
\frac{1}{2} \frac{d}{d t}\left\|\varepsilon_{h}\right\|^{2}+\left\|e_{h, t}\right\|^{2}=\left(\rho_{t}, e_{h, t}\right) \leqq \frac{1}{2}\left\|\rho_{t}\right\|^{2}+\frac{1}{2}\left\|e_{h, t}\right\|^{2},
$$

so that

$$
\left\|\varepsilon_{h}(t)\right\|^{2} \leqq \int_{0}^{t}-\left\|\rho_{t}\right\|^{2} d \tau \leqq C h^{2 s} \int_{0}^{t}\left\|u_{t}\right\|_{s}^{2} d \tau .
$$

In view of (2.8) this shows (2.4). 
In order, finally, to show (2.5) we note that $(2.6 \mathrm{~b})$ in conjunction with Lemma 1.3 shows

$$
\left\|e_{h}(t)\right\|_{L_{x}(\Omega)} \leqq C \log \frac{1}{h}\left\|\varepsilon_{h}(t)\right\| \leqq C h^{s} \log \frac{1}{h}\left(\int_{0}^{t}\left\|u_{t}\right\|_{s}^{2} d \tau\right)^{1,2}
$$

and that hence (2.5) follows by (2.9). This completes the proof.

We shall now discuss some error estimates for the homogeneous equation [i.e. $f=0$ in (2.1)]. In doing so we shall have reason to use the regularity of the solution for $t>0$. For this purpose we shall now restrict ourselves to the situation that $\Omega$ is a convex domain with smooth boundary and that we are dealing with the case of second order accurate spaces $(r=2)$ which was given special attention in the latter part of section 1 .

Let $\left\{\lambda_{j}\right\}_{1}^{\infty}$ be the eigenvalues (in non-decreasing order) and $\left\{\varphi_{j}\right\}_{1}^{\infty}$ the $\left(L_{2}\right.$ orthonormal) eigenfunctions of the elliptic problem

$$
-\Delta \varphi=\lambda \varphi \quad \text { in } \Omega, \quad \varphi=0 \text { on } \Gamma \text {. }
$$

For $s \geqq 0$, let $\dot{H}^{s}=\dot{H}^{s}(\Omega)$ be the space defined by the norm

$$
\|v\|_{\dot{H}^{s}}=\left(\sum_{j=1}^{\infty} \lambda_{j}^{s}\left(v, \varphi_{j}\right)^{2}\right)^{1 / 2}
$$

and recall ( $c f .[5])$ that for $s$ a non-negative integer, $\dot{H}^{s}$ consists of the functions $v$ in $H^{s}(\Omega)$ which satisfy the boundary conditions $\Delta^{j} v=0$ on $\Gamma$ for $j<s / 2$ and that the norm in $\dot{H}^{s}$ is equivalent to the usual norm in $H^{s}(\Omega)$. With this notation, the solution

$$
u(t)=\sum_{j=1}^{\infty} e^{-\lambda, t}\left(g, \varphi_{j}\right) \varphi_{j},
$$

of the homogeneous equation belongs to $\dot{H}^{s}$ for $t$ positive for any $s>0$, and

$$
\|u(t)\|_{\dot{H}^{s}} \leqq C t^{-(s-j) / 2}\|g\|_{\dot{H}^{s}} \quad \text { for } \quad j \leqq s .
$$

In our first result for the homogeneous equation we shall assume that the solution is smooth for $t \geqq 0$. In the following result we shall then consider estimates for $t$ strictly positive which only require the initial data to belong to $L_{2}(\Omega)$. In the former result we use for the initial data the elliptic projection of $g$ and in the latter its $L_{2}$ projection onto $V_{h}$.

THEOREM 2.2: Under the present assumptions about $\Omega, V_{h}$, and $H_{h}$, consider the homogeneous equation and let $u_{h}(0)=-T_{h} \Delta g$ be the elliptic projection of $g$. Then for $t \geqq 0$,

$$
\begin{gathered}
\left\|u_{h}(t)-u(t)\right\| \leqq C h^{2}\|g\|_{\dot{H}^{2}}, \\
\left\|\sigma_{h}(t)-\sigma(t)\right\| \leqq C h^{2}\|g\|_{\dot{H}^{3}},
\end{gathered}
$$


and

$$
\left\|u_{h}(t)-u(t)\right\|_{L_{\infty}(\Omega)} \leqq C h^{2} \log \frac{1}{h}\|g\|_{\dot{H}^{3}} .
$$

Proof: In the same way as in the proof of Theorem 2.1 we obtain

$$
\frac{1}{2} \frac{d}{d t}\left\|e_{h}\right\|^{2}+\left\|\varepsilon_{h}\right\|^{2}=\left(\rho_{t}, e_{h}\right)
$$

from which we conclude

$$
\frac{d}{d t}\left(t\left\|e_{h}\right\|^{2}\right) \leqq t^{2}\left\|\rho_{t}\right\|^{2}+2\left\|e_{h}\right\|^{2},
$$

or

$$
t\left\|e_{h}(t)\right\|^{2} \leqq \int_{0}^{t} \tau^{2}\left\|\rho_{t}\right\|^{2} d \tau+2 \int_{0}^{t}\left\|e_{h}\right\|^{2} d \tau .
$$

For the purpose of estimating the last term we introduce

$$
\mathscr{E}_{h}(t)=\int_{0}^{t} \varepsilon_{h} d \tau
$$

By integration of the first error equation ( $2.6 a)$ with respect to $t$, recalling that $e_{h}(0)=0$ we obtain

$$
\left(e_{h}, v_{h}\right)-\left(\operatorname{div} \mathscr{E}_{h}, v_{h}\right)=\left(\rho-\rho(0), v_{h}\right), \quad \forall v_{h} \in V_{h},
$$

and the second equation (2.6 b) may be written

$$
\left(\mathscr{E}_{h, t}, \chi_{h}\right)+\left(e_{h}, \operatorname{div} \chi_{h}\right)=0, \quad \forall \chi_{h} \in H_{h} .
$$

Setting $v_{h}=e_{h}, \chi_{h}=\mathscr{E}_{h}$ and adding we obtain

$$
\frac{1}{2} \frac{d}{d t}\left\|\mathscr{E}_{h}\right\|^{2}+\left\|e_{h}\right\|^{2}=\left(\rho-\rho(0), e_{h}\right) \leqq \frac{1}{2}\|\rho-\rho(0)\|^{2}+\frac{1}{2}\left\|e_{h}\right\|^{2},
$$

so that

$$
\int_{0}^{t}\left\|e_{h}\right\|^{2} d \tau \leqq \int_{0}^{t}\|\rho-\rho(0)\|^{2} d \tau .
$$

Together with (2.13) this yields

$$
\left\|e_{h}(t)\right\| \leqq C \sup _{\tau \leq t}\left(\tau\left\|\rho_{t}(\tau)\right\|+\|\rho(\tau)\|\right) .
$$

vol. $15, \mathrm{n}^{\circ} 1,1981$ 
Here

$$
\begin{gathered}
\|\rho(\tau)\| \leqq C h^{2}\|u(\tau)\|_{2} \leqq C h^{2}\|g\|_{H^{2}}, \\
\tau\left\|\rho_{t}(\tau)\right\| \leqq C \tau h^{2}\left\|u_{t}(\tau)\right\|_{2} \leqq C h^{2}\|g\|_{H^{2}}
\end{gathered}
$$

so that

$$
\left\|u_{h}(t)-u(t)\right\| \leqq\left\|e_{h}(t)\right\|+\|\rho(t)\| \leqq C h^{2}\|g\|_{H^{2}},
$$

which is $(2.10)$.

The estimates (2.11) and (2.12) follow easily from (2.4) and (2.5) since for the homogeneous equation

$$
\|u(t)\|_{3} \leqq C\|g\|_{H^{3}}
$$

and

$$
\int_{0}^{t}\left\|u_{t}\right\|_{2}^{2} d \tau \leqq C \int_{0}^{t} \sum_{J=1}^{\infty} \lambda_{J}^{4}\left(v, \varphi_{J}\right)^{2} e^{-2 \lambda, t} d \tau \leqq C\|g\|_{H^{3}}
$$

This completes the proof of the theorem.

THEOREM 2.3: Under the present conditions on $\Omega, V_{h}$ and $H_{h}$, consider the homogeneous equation and let $u_{h}(0)=P_{h} v$. Then for $t>0$,

$$
\begin{gathered}
\left\|u_{h}(t)-u(t)\right\| \leqq C h^{2} t^{-1}\|g\|, \\
\left\|\sigma_{h}(t)-\sigma(t)\right\| \leqq C h^{2} t^{-3 / 2}\|g\|,
\end{gathered}
$$

and

$$
\left\|u_{h}(t)-u(t)\right\|_{\mathcal{L}_{\infty}(\Omega)} \leqq C h^{2} \log \frac{1}{h} t^{-3 / 2}\|g\|
$$

Proof: Recall from above that the continuous and semidiscrete problems may be written

$$
T u_{t}+u=0 \quad \text { for } t>0, u(0)=g
$$

and

$$
T_{h} u_{h, t}+u_{h}=0 \quad \text { for } \quad t>0, \quad u_{h}(0)=P_{h} g,
$$

where $T_{h}$ satisfies the properties of lemma 1.5. It therefore follows from theorem 3.2 of [4] that

$$
\left\|\left(\frac{\partial}{\partial t}\right)^{J}\left(u_{h}(t)\right)-u(t)\right\| \leqq C h^{2} t^{-1-J}\|g\|,
$$

which in particular shows (2.14). 
For the purpose of showing (2.15) we use again the elliptic projection $\left(\tilde{u}_{h}, \tilde{\sigma}_{h}\right)$ of $(u, \sigma)$ and have as in the proof of theorem 2.1,

$$
\left(e_{h, t}, e_{h}\right)+\left\|\varepsilon_{h}\right\|^{2}=\left(\rho_{t}, e_{h}\right),
$$

so that

$$
\left\|\varepsilon_{h}\right\|^{2} \leqq\left(\left\|\rho_{t}\right\|+\left\|e_{h, t}\right\|\right)\left\|e_{h}\right\|
$$

Here

$$
\begin{gathered}
\left\|e_{h}(t)\right\| \leqq\left\|u_{h}(t)-u(t)\right\|+\|\rho(t)\| \leqq C h^{2} t^{-1}\|g\|, \\
\left\|\rho_{t}(t)\right\| \leqq C h^{2}\left\|u_{t}(t)\right\|_{2} \leqq C h^{2} t^{-2}\|g\|,
\end{gathered}
$$

and

$$
\left\|e_{h, t}(t)\right\| \leqq\left\|\left(u_{h}(t)-u(t)\right)_{t}\right\|+\left\|\rho_{t}(t)\right\| \leqq C h^{2} t^{-2}\|g\|,
$$

so that

$$
\left\|\varepsilon_{h}(t)\right\| \leqq C h^{2} t^{-3 / 2}\|g\|
$$

Since

$$
\left\|\tilde{\sigma}_{h}(t)-\sigma(t)\right\| \leqq C h^{2}\|u(t)\|_{3} \leqq C h^{2} t^{-3 / 2}\|g\|,
$$

this completes the proof of (2.15).

In order, finally, to show (2.16), note that by Lemma 1.2 and $(2.6 b)$ :

$$
\left\|e_{h}(t)\right\|_{L_{\infty}(\Omega)} \leqq C \log \frac{1}{h}\left\|\varepsilon_{h}(t)\right\| \leqq C h^{2} \log \frac{1}{h} t^{-3 / 2}\|g\| .
$$

Together with

$$
\|\rho(t)\|_{L_{\infty}(\Omega)} \leqq C h^{2} \log \frac{1}{h}\|u(t)\|_{3} \leqq C h^{2} \log \frac{1}{h} t^{-3 / 2}\|g\|,
$$

this establishes (2.16) and completes the proof of the theorem.

\section{THE STATIONARY STOKES' EQUATIONS}

We now turn to the steady state Stokes' equations in a convex plane domain $\Omega$ with smooth boundary $\Gamma$,

$$
\left.\begin{array}{c}
-\frac{1}{2} \Delta u+\nabla p=f \quad \text { in } \Omega, \\
u \equiv \frac{\partial u_{1}}{\partial x_{1}}+\frac{\partial u_{2}}{\partial x_{2}}=0 \text { in } \Omega, \\
u=0 \text { on } \Gamma .
\end{array}\right\}
$$


In applications $u=\left(u_{1}, u_{2}\right)$ represents the velocity and $p$ the pressure of an incompressible Newtonian fluid with viscosity equal to $1 / 2$ and $f=\left(f_{1}, f_{2}\right)$ is a given force. We shall consider a mixed finite element method for this problem which is analogous to that used in Section 1 for Poisson's equation and which uses finite elements devised in [12] for the equations of elasticity. In order to motivate the variational formulation on which this method is based, we shall use an alternative statement of (3.1) which is in fact the formulation of Stokes' equations in natural physical variables used in continuum mechanics.

We begin with some notation. For a given symmetric $2 \times 2$ matrix $\sigma=\left(\sigma_{i j}\right)$, let $\operatorname{tr} \sigma=\sigma_{11}+\sigma_{22}$ and define, with $\delta$ the unit matrix, the deviatoric part of $\sigma$ by $\bar{\sigma}=\sigma-(1 / 2) \operatorname{tr} \sigma . \delta$. We then always have the unique decomposition

$$
\sigma=\bar{\sigma}+q \cdot \delta \quad \text { with } \quad \operatorname{tr} \bar{\sigma}=0, \quad q=\frac{1}{2} \operatorname{tr} \sigma .
$$

Also set

$$
\varepsilon_{i j}(u)=\frac{1}{2}\left(\frac{\partial u_{i}}{\partial x_{j}}+\frac{\partial u_{j}}{\partial x_{i}}\right), \quad i, j=1,2
$$

and notice that $\operatorname{tr} \varepsilon(u)=\operatorname{div} u$ so that in particular for $(u, p)$ a solution of (3.1), $\operatorname{tr} \varepsilon(u)=0$ or $\varepsilon(u)=\overline{\varepsilon(u)}$.

We now introduce the new dependent variable

$$
\sigma=\varepsilon(u)-p \cdot \delta,
$$

and note that for the 2-vector

$$
\operatorname{div} \sigma=\left((\operatorname{div} \sigma)_{i}\right)=\left(\partial u_{i 1} / \partial x_{1}+\partial u_{i 2} / \partial x_{2}\right)
$$

we have

$$
\operatorname{div} \sigma=\operatorname{div} \varepsilon(u)-\operatorname{div}(p \cdot \delta)=\frac{1}{2} \Delta u-\nabla p .
$$

We thus find that for $(u, p)$ a solution of $(3.1),(u, \sigma)$ solves the equations

$$
\begin{gathered}
-\operatorname{div} \sigma=f \text { in } \Omega, \\
\bar{\sigma}=\varepsilon(u) \text { in } \Omega, \\
u=0 \text { on } \Gamma .
\end{gathered}
$$

In continuum mechanics, $\sigma$ and $\varepsilon(u)$ represent the stress and strain tensors, respectively. 
In the present context Green's formula takes the form

$$
(\varepsilon(u), \chi)=\int_{\Gamma}(\chi \cdot n) \cdot u d s-(u, \operatorname{div} \chi),
$$

where $\chi \cdot n=\left(\chi_{i 1} n_{1}+\chi_{i 2} n_{2}\right)$ is the component of $\chi=\left(\chi_{i j}\right)$ in the direction of the exterior normal $n=\left(n_{1}, n_{2}\right)$ to $\Gamma$, and where (., . ) denote the inner products in the appropriate $L_{2}(\Omega)^{m}$ spaces, $m=2,4$.

Now, introducing the spaces

$$
\begin{gathered}
V=L_{2}(\Omega)^{2}, \\
H=\left\{\chi=\left(\chi_{i j}\right) ; \chi_{i j}=\chi_{j i} \in L_{2}(\Omega), i, j=1,2, \operatorname{div} \chi \in L_{2}(\Omega)^{2}\right\},
\end{gathered}
$$

and using the above Green's formula we see that $(u, \sigma)$ solves the following variational problem: find $(u, \sigma) \in V \times H$ such that

$$
\begin{array}{ll}
(\operatorname{div} \sigma, v)+(f, v)=0, & \forall v \in V, \\
(\bar{\sigma}, \bar{\chi})+(u, \operatorname{div} \chi)=0, & \forall \chi \in H .
\end{array}
$$

Notice that, formally, by Green's formula, the second equation contains both the boundary condition $u=0$ on $\Gamma$ and the equation $\varepsilon(u)=\bar{\sigma}$ in $\Omega$, with in particular the incompressibility condition $\operatorname{div} u=\operatorname{tr} \varepsilon(u)=0$.

We quote from [15] the fact that for given $f \in W_{q}^{m}(\Omega)$ with $1<q<\infty, m \geqq 0$, the problem (3.1) has a unique solution $(u, p) \in W_{q}^{m+2}(\Omega) \times W_{q}^{m+1}(\Omega) / R$ ( $p$ unique up to an additive constant) such that

$$
\|u\|_{W_{q}^{m+2}(\Omega)}+\|p\|_{W_{q}^{m+1}(\Omega) / R} \leqq C\|f\|_{W_{q}^{m}(\Omega)} .
$$

Translated into the notation introduced above this regularity estimate implies for the stress tensor $\sigma$,

$$
\|\sigma \mid\|_{W_{q}^{m+1}(\Omega)} \leqq C\|f\|_{W_{q}^{m}(\Omega)},
$$

where

$$
\|\| \sigma\|\|_{W_{q}^{s}(\Omega)}=\|\bar{\sigma}\|_{W_{q}^{s}(\Omega)}+\|\operatorname{tr} \sigma\|_{W_{q}^{s}(\Omega) / R} .
$$

In analogy with our previous conventions we shall write \|\|$\cdot\|\|_{s}$ for $\|\mid\| \|_{W_{2}(\Omega)}$, with $s$ sometimes omitted when zero. For scalar functions $q$ we also use

$$
\|\mid q\|\|=\| q \|_{L_{2}(\Omega) / R} .
$$

For the purpose of defining a discrete analogue of the problem (3.2) we now introduce finite dimensional spaces $V_{h} \subset V$ and $H_{h} \subset H$. As in the second part of vol. $15, \mathrm{n}^{\circ} 1,1981$ 
Section 1, let $\mathscr{T}_{h}=\{K\}$ be a quasi-uniform regular triangulation of $\Omega$ such that the polygonal domain $\Omega_{h}$ determined by $U K$ has its vertices on $\Gamma$. For each $K$ let $\left\{T_{K, J}\right\}_{1}^{3}$ be the subtriangles obtained by joining the center of gravity of $K$ with the vertices of $K$. For $K$ a boundary triangle denote by $\tilde{K}$ the extension to a triangle with one curved edge and define similarly $\widetilde{T}_{K, J}$ for boundary triangles $T_{K, J}$. For convenience, we identify for other triangles $K$ with $\widetilde{K}$ and $T_{K, J}$ with $\widetilde{T}_{K, J}$. Set now

$$
V_{h}=\left\{v=\left(v_{1}, v_{2}\right) \in V ;\left.\left.v\right|_{K} \in \mathscr{P}_{1}^{2}\right|_{K}, \forall K \in \mathscr{T}_{h} ; v=0 \text { in } \Omega \backslash \Omega_{h}\right\},
$$

and

$$
H_{h}=\left\{\chi \in H ;\left.\chi\right|_{\tilde{K}} \in H(\tilde{K}), \forall K \in \mathscr{T}_{h}\right\},
$$

where

$$
H(\tilde{K})=\left\{\chi \in L_{2}(\tilde{K})^{4} ; \chi_{12}=\chi_{21}, \operatorname{div} \chi \in L_{2}(\tilde{K})^{2},\left.\left.\chi\right|_{\tilde{T}_{K, J}} \in \mathscr{P}_{1}^{4}\right|_{\tilde{T}_{K, J}}\right\}
$$

Thus, $V_{h}$ consists of vectors with two components which are linear on each $K$, without continuity requirements across interelement boundaries, and which vanish outside $\Omega_{h}$. Further, $H_{h}$ consists of symmetric $2 \times 2$ matrices, the elements of which are linear on each subtriangle $T_{K, J}$ of the elements $K$, for which the normal component $\chi \cdot n$ is continuous across both interelement boundaries and across the boundaries between the subtriangles $T_{K, J}$. The functions in $H_{h}$ are defined in $\Omega \backslash \Omega_{h}$ by using the same linear function in $\widetilde{T}_{K, J}$ as in $T_{K, j}$.

We recall from [12] that $\chi \in H_{h}$ is uniquely determined by the following degrees of freedom:

(i) the value of $\chi \cdot n$ at two points on each edge $S$ of $\mathscr{T}_{h}$ where $n$ is a unit normal to $S(12$ conditions for each $K)$;

(ii) the value of $\int_{K} \chi_{i j} d x, i, j=1,2$ for each $K \in \mathscr{T}_{h}(3$ conditions for each $K)$.

With the above choices of $V_{h}$ and $H_{h}$ we now pose the following discrete analogue of (3.2): Find $\left(u_{h}, \sigma_{h}\right) \in V_{h} \times H_{h}$ such that

$$
\begin{aligned}
\left(\operatorname{div} \sigma_{h}, v_{h}\right)+\left(f, v_{h}\right)=0, & \forall v_{h} \in V_{h}, \\
\left(\bar{\sigma}_{h}, \bar{\chi}_{h}\right)+\left(u_{h}, \operatorname{div} \chi_{h}\right)=0, & \forall \chi_{h} \in H_{h} .
\end{aligned}
$$

Setting $\chi_{h}=q_{h} \delta$ in $(3.5 b)$ we find since $\operatorname{div}\left(q_{h} \delta\right)=\nabla q_{h}$ and $\overline{q_{h} \delta}=0$ that for $\left(u_{h}, \sigma_{h}\right)$ a solution we have

$$
u_{h} \in \stackrel{\circ}{V}_{h}=\left\{v_{h} \in V_{h} ;\left(u_{h}, \nabla q_{h}\right)=0, \forall q_{h} \text { with } q_{h} \delta \in H_{h}\right\} .
$$

The condition $u_{h} \in \check{V}_{h}$ may be interpreted as a discrete incompressibility condition. 
For the analysis of this discrete problem we shall need a sequence of lemmas which correspond in an obvious fashion to those of Section 1.

Lemma 3.1: There exists a linear operator $\Pi_{h}: H \rightarrow H_{h}$ such that

$$
\begin{gathered}
\left(\operatorname{div} \Pi_{h} \chi, v_{h}\right)=\left(\operatorname{div} \chi, v_{h}\right), \quad \forall v_{h} \in V_{h}, \quad \chi \in H, \\
\left\|\Pi_{h} \chi-\chi\right\| \leqq C h^{s}\|\chi\|_{s} \quad \text { for } \quad s=1,2, \\
\left\|\overline{\Pi_{h} \chi}\right\| \leqq C\|\chi\|_{W_{1}^{1}(\Omega)} .
\end{gathered}
$$

Proof: We may define $\Pi_{h}$ in the same way as in Section 1 by requiring

$$
\begin{gathered}
\int_{s} v \cdot\left(\Pi_{h} \chi-\chi\right) \cdot n d s=0, \quad \text { for } \quad v \text { linear, for each edge } S \text { of } \mathscr{T}_{h}, \\
\int_{K}\left(\Pi_{h} \chi-\chi\right) d x=0, \quad \text { for all } K \in \mathscr{T}_{h} .
\end{gathered}
$$

We obtain in the same way as before, for $v_{h} \in V_{h}$,

$$
\int_{K} \operatorname{div}\left(\Pi_{h} \chi-\chi\right) v_{h} d x=\int_{\partial K}\left(\Pi_{h} \chi-\chi\right) \cdot n v_{h} d s-\int_{K} \varepsilon\left(v_{h}\right)\left(\Pi_{h} \chi-\chi\right) d x=0,
$$

which shows (3.6) since $v_{h}=0$ in $\Omega \backslash \Omega_{h}$. For the approximation property (3.7) we note that as in Section 1, using a trace theorem and the fact that $\Pi_{h}$ reproduces linear functions,

$$
\left\|\Pi_{h} \chi-\chi\right\| \leqq C h^{s}\|\chi\|_{s} . \quad \text { for } \quad s=1,2 .
$$

The present estimate now follows at once since, in particular, $\Pi_{h}$ reproduces constants. Finally, as in Section 1 we have by the appropriate trace theorem

$$
\left\|\bar{\Pi}_{h} \chi\right\| \leqq\left\|\Pi_{h} \chi\right\| \leqq C\|\chi\|_{W_{1}^{1}(\Omega)} \leqq C\left(\|\bar{\chi}\|_{W_{1}^{1}(\Omega)}+\|\operatorname{tr} \chi\|_{W_{1}^{1}(\Omega)}\right) .
$$

Letting now $c \in R$ be arbitrary and noticing that $\overline{\Pi_{h}(\chi+(1 / 2) c \delta)}=\bar{\Pi}_{h} \chi$ we have

$$
\left\|\overline{\Pi_{h} \chi}\right\| \leqq C\left(\|\bar{\chi}\|_{W_{1}^{1}(\Omega)}+\|\operatorname{tr} \chi+c\|_{W_{1}^{1}(\Omega)}\right),
$$

which implies (3.8).

Lemma 3.2 : There is a constant $C$ such that

In particular, if $\chi_{h} \in H_{h}$ satisfies

$$
\left\|\operatorname{div} \chi_{h}\right\| \leqq C \sup _{v_{h} \in V_{h}} \frac{\left(\operatorname{div} \chi_{h}, v_{h}\right)}{\left\|v_{h}\right\|} \quad \text { for } \quad \chi_{h} \in H_{h} .
$$

then $\operatorname{div} \chi_{h}=0$ in $\Omega$.

$$
\left(\operatorname{div} \chi_{h}, v_{h}\right)=0, \quad \forall v_{h} \in V_{h},
$$


Proof: We have for $\left(v_{h}, \chi_{h}\right) \in V_{h} \times H_{h}$,

$$
\begin{aligned}
\left(\operatorname{div} \chi_{h}, v_{h}\right)=\left.\sum_{K \in \mathscr{T}_{h}} \sum_{J=1}^{3} \operatorname{div} \chi_{h}\right|_{T_{K, J}} \int_{T_{K} J} v_{h} d x & \\
& =\sum_{K \in \mathscr{T}_{h}} \sum_{J=1}^{3}\left(\operatorname{div} \chi_{h}\right)\left(P_{K, J}\right) v_{h}\left(P_{K, j}\right) m\left(T_{K, j}\right),
\end{aligned}
$$

where $P_{K, J}$ is the center of gravity of $T_{K, J}$. We also have

$$
\left\|v_{h}\right\|^{2} \leqq C \sum_{K \in \mathscr{T}_{h}} \sum_{J=1}^{3}\left|v_{h}\left(P_{K, J}\right)\right|^{2} m\left(T_{K, J}\right)
$$

and

$$
\left\|\operatorname{div} \chi_{h}\right\|^{2} \leqq \sum_{K \in \mathscr{T}_{k}} \sum_{J=1}^{3}\left|\left(\operatorname{div} \chi_{h}\right)\left(P_{K, J}\right)\right|^{2} m\left(T_{K, J}\right) \leqq C\left\|\operatorname{div} \chi_{h}\right\|^{2},
$$

from which the lemma easily follows.

LEMMA 3.3: There is an operator $\widetilde{Q}_{h}: V \rightarrow V_{h}$ such that

$$
\left(\operatorname{div} \chi_{h}, \widetilde{Q}_{h} v\right)=\left(\operatorname{div} \chi_{h} . v\right), \quad \forall \chi_{h} \in H_{h},
$$

and such that

$$
\left\|\widetilde{Q}_{h} v-v\right\| \leqq C h^{s}\|\varepsilon(v)\|_{s-1} \quad \text { for } \quad s=1,2, \quad \text { if } v=0 \text { on } \Gamma,
$$

and

$$
\left\|\widetilde{Q}_{h} v-v\right\|_{L_{\infty}(\Omega)} \leqq C h^{2}\left(\log \frac{1}{h}\right)^{1 / 2}\|\varepsilon(v)\|_{2} \quad \text { if } \quad v=0 \quad \text { on } \Gamma
$$

If $\operatorname{div} v=0$ we have $\widetilde{Q}_{h} v \in \stackrel{\circ}{V}_{h}$.

Proof: We define $\widetilde{Q}_{h}$ and also an auxiliary operator $Q_{h}: V \rightarrow V_{h}$ as follows. For $K \in \mathscr{T}_{h}$ we determine the linear functions $\left.Q_{h} v\right|_{K}$ and $\left.\widetilde{Q}_{h} v\right|_{K}$ by demanding that

$$
\begin{aligned}
& Q_{h} v\left(P_{K, j}\right)=\frac{1}{m\left(T_{K, J}\right)} \int_{T_{K, J}} v d x, \\
& \widetilde{Q}_{h} v\left(P_{K, J}\right)=\frac{1}{m\left(T_{K, j}\right)} \int_{\widetilde{T}_{K, J}} v d x,
\end{aligned}
$$


and set $Q_{h} v=\widetilde{Q}_{h} v=0$ in $\Omega \backslash \Omega_{h}$. Since $\operatorname{div} \chi_{h}$ is constant in each $T_{K, j}$ we have

$$
\begin{aligned}
\int_{K} \widetilde{Q}_{h} v \operatorname{div} \chi_{h} d x=\sum_{j=1}^{3}\left(\operatorname{div} \chi_{h}\right)\left(P_{K, j}\right) & \widetilde{Q}_{h} v\left(P_{K, j}\right) m\left(T_{K, j}\right) \\
= & \sum_{j=1}^{3}\left(\operatorname{div} \chi_{h}\right)\left(P_{K, j}\right) \int_{\tilde{T}_{K, j}} v d x=\int_{\tilde{K}} v \operatorname{div} \chi_{h} d x,
\end{aligned}
$$

so that (3.9) follows by summation over $K$.

In order to show the error estimates for $\tilde{Q}_{h}$ we first note that since $\left.Q_{h}\right|_{K}$ reproduces linear functions and is bounded in $L_{p}(K)$ we have

$$
\left\|Q_{h} v-v\right\|_{L_{p}\left(\Omega_{h}\right)} \leqq C h^{s}\|v\|_{W_{p}^{s}(\Omega)} \quad \text { for } \quad 0 \leqq s \leqq 2,
$$

and hence, in the same way as in section 1 ,

$$
\left\|Q_{h} v-v\right\|_{L_{x}\left(\Omega_{h}\right)} \leqq C h^{2}\left(\log \frac{1}{h}\right)^{1 / 2}\|v\|_{3} .
$$

Further, since $Q_{h} v$ and $\widetilde{Q}_{h} v$ agree except at boundary triangles and since when $\widetilde{T}_{K, 1} \neq T_{K, j}$,

$$
\left|\left(\widetilde{Q}_{h} v-Q_{h} v\right)\left(P_{K, j}\right)\right|=\frac{1}{m\left(T_{K, j}\right)}\left|\int_{\tilde{T}_{K, j} \backslash T_{K, J}} \imath d x\right| \leqq C h^{-(2 / p)}\|v\|_{L_{p}\left(\widetilde{T}_{K, j} \backslash T_{K, j}\right)},
$$

we find easily

$$
\left\|\widetilde{Q}_{h} v-Q_{h} v\right\|_{L_{p}(\Omega)} \leqq C\|v\|_{L_{p}\left(\Omega \backslash \Omega_{h}\right)} \leqq C h^{2}\|v\|_{\psi_{p}^{\prime}(\Omega)} \quad \text { if } \quad v=0 \text { on } \Gamma .
$$

Together these estimates prove that

$$
\left\|\widetilde{Q}_{h} v-v\right\| \leqq C h^{s}\|\nabla v\|_{s-1} \quad \text { for } \quad s=1,2, \quad \text { if } v=0 \text { on } \Gamma,
$$

and

$$
\mid \widetilde{Q}_{h} v-v\left\|_{L_{x}(\Omega)} \leqq C h^{2}\left(\log \frac{1}{h}\right)^{1 / 2}\right\| \nabla v \|_{2}, \quad \text { if } \quad v=0 \quad \text { on } \Gamma,
$$

where we have eliminated the $L_{2}$-norm of $v$ on the right hand side by Friedrichs' inequality. The desired error estimates now follow from Korn's inequality (cf. [8]): There exists a constant $C$ such that

$$
\|\nabla v\|_{s} \leqq C\|\varepsilon(v)\|_{s} \quad \text { for } v \in H_{0}^{1}(\Omega)^{2} \cap H^{s+1}(\Omega)^{2}, \quad s \geqq 0 .
$$

The final statement of the lemma follows from the fact that for $q_{h} \in H_{h}$,

$$
\left(\nabla \operatorname{tr} q_{h}, \widetilde{Q}_{h} v\right)=2\left(\operatorname{div}\left(q_{h} \delta\right), v\right)=\left(\nabla \operatorname{tr} q_{h}, v\right)=\left(\operatorname{tr} q_{h}, \operatorname{div} v\right)=0 .
$$


LeMma 3.4: Let $2 \leqq p \leqq \infty$. There are constants $C_{p}$ and $C$ such that if $w_{h} \in V_{h}$ and $\omega \in L_{2}(\Omega)^{4}$ satisfy

$$
\left(\bar{\omega}, \bar{\chi}_{h}\right)+\left(w_{h}, \operatorname{div} \chi_{h}\right)=0, \quad \forall \chi_{h} \in H_{h},
$$

then

$$
\left\|w_{h}\right\|_{L_{p}(\Omega)} \leqq C_{p}\|\bar{\omega}\| \quad \text { if } \quad p<\propto
$$

and

$$
\left\|w_{h}\right\|_{L_{x}(\Omega)} \leqq C \log \frac{1}{h}\|\bar{\omega}\| .
$$

Proof: Let $p<\infty$ and $\psi \in L_{q}(\Omega)$ where $p^{-1}+q^{-1}=1$. Let $(\varphi, q)$ be the solution of the Stokes' problem (3.1) with $f$ replaced by $\psi$ so that with $\eta=\varepsilon(\varphi)-q \cdot \delta$,

$$
\begin{gathered}
-\operatorname{div} \eta=\psi \text { in } \Omega, \\
\bar{\eta}=\varepsilon(\varphi) \text { in } \Omega, \\
\varphi=0 \text { on } \Gamma .
\end{gathered}
$$

By the elliptic regularity result (3.4) we have for $q>1$,

$$
\|\| \eta\|\|_{W_{q}^{1}(\Omega)} \leqq C_{q}\|\psi\|_{L_{q}(\Omega)}
$$

We have following the lines of the proof of lemma 1.2,

$$
\begin{aligned}
\left(w_{h}, \psi\right)=-\left(w_{h}, \operatorname{div} \eta\right) & =-\left(w_{h}, \operatorname{div} \Pi_{h} \eta\right)=\left(\bar{\omega}, \bar{\Pi}_{h} \bar{\eta}\right) \\
\leqq & \leqq \bar{\omega}\|\cdot\| \overline{\Pi_{h} \eta}\|\leqq C\| \bar{\omega}\|.\|\|\eta\|\left\|_{W_{q}^{1}(\Omega)} \leqq C_{q}\right\| \bar{\omega}\|\cdot\| \psi \|_{L^{q}(\Omega)},
\end{aligned}
$$

which shơws (3.10). Observing that again $C_{q}=0(p)$ as $p \rightarrow \infty$, we conclude the maximum-norm estimate (3.11) as in the proof of Lemma 1.2, using an inverse estimate analogous to $(1.7)$ with $p=\log 1 / h$.

Lemma 3.5: Assume that $\left(w_{h}, \omega\right) \in V_{h} \times H$ satisfy

$$
\begin{gathered}
\left(\bar{\omega}, \chi_{h}\right)+\left(w_{h}, \operatorname{div} \chi_{h}\right)=0, \quad \forall \chi_{h} \in H_{h}, \\
\left(\operatorname{div} \omega, v_{h}\right)=0, \quad \forall v_{h} \in V_{h} .
\end{gathered}
$$

Then

$$
\left\|w_{h}\right\| \leqq C\left\{h\|\bar{\omega}\|+h^{2}\|\operatorname{div} \omega\|\right\} .
$$

Proof: Let $\psi \in L_{2}(\Omega)$ and let $(\varphi, \eta) \in V \times H$ be the solution of (3.12) used in the proof of Lemma 3.4. We have by (3.6) and (3.13),

$$
\begin{aligned}
\left(w_{h}, \psi\right)=-\left(w_{h}, \operatorname{div} \eta\right)=-\left(w_{h}, \operatorname{div} \overline{\Pi_{h} \eta}\right)=\left(\bar{\omega}, \overline{\Pi_{h} \eta}\right) & \\
& =\left(\bar{\omega}, \overline{\Pi_{h} \eta}-\bar{\eta}\right)+(\bar{\omega}, \bar{\eta})=I_{1}+I_{2} .
\end{aligned}
$$


Here

$$
\left|I_{1}\right| \leqq\|\bar{\omega}\| \cdot\left\|\bar{\Pi}_{h} \eta \bar{\eta}-\bar{\eta}\right\| \leqq C\|\bar{\omega}\| . h\|\eta\|\left\|_{1} \leqq C h\right\| \bar{\omega}\|.\| \psi \|
$$

Further, noticing that

$$
(\operatorname{tr} \omega \cdot \delta, \varepsilon(\varphi))=(\operatorname{tr} \omega, \operatorname{div} \varphi)=0,
$$

we have using Green's formula, (3.14), Lemma 3.3, and (3.3),

$$
\begin{aligned}
\mathrm{I}_{2}=(\bar{\omega}, \varepsilon(\varphi))= & (\omega, \varepsilon(\varphi))=-(\operatorname{div} \omega, \varphi) \\
& =-\left(\operatorname{div} \omega, \varphi-\widetilde{Q}_{h} \varphi\right) \leqq C h^{2}\|\varphi\|_{2}\|\operatorname{div} \omega\| \leqq C h^{2}\|\psi\| \cdot\|\operatorname{div} \omega\| .
\end{aligned}
$$

Together these estimates prove the lemma.

Lemma 3.6: Assume that $\left(w, \omega_{h}\right) \in L_{2}(\Omega)^{2} \times H_{h}$ satisfy

$$
\left(\operatorname{div} \omega_{h}, v_{h}\right)+\left(w, v_{h}\right)=0, \quad \forall v_{h} \in V_{h} .
$$

Then

$$
\left\|\operatorname{tr} \omega_{h}\right\| \| \leqq C\left(\left\|\bar{\omega}_{h}\right\|+\|w\|\right)
$$

Proof: Recall from (8) that

$$
\|p\| \equiv C\|\nabla p\|_{H^{-1}(\Omega)} \equiv C \sup _{v \in H_{0}^{1}(\Omega)^{2}} \frac{(\nabla p, v)}{\|v\|_{1}} .
$$

We shall therefore consider $\nabla \operatorname{tr} \omega_{h}$. By Green's formula we have for $v \in H_{0}^{1}(\Omega)^{2}$,

$$
\left(\nabla \operatorname{tr} \omega_{h}, v\right)=\left(\operatorname{div}\left(\operatorname{tr} \omega_{h} \cdot \delta\right), v\right)=-\left(\operatorname{tr} \omega_{h} \cdot \delta, \varepsilon(v)\right)=2\left(\bar{\omega}_{h}, \varepsilon(v)\right)-2\left(\omega_{h}, \varepsilon(v)\right)
$$

Here clearly

$$
\left|\left(\bar{\omega}_{h}, \varepsilon(v)\right)\right| \leqq C\left\|\bar{\omega}_{h}\right\| \cdot\|v\|_{1}
$$

and using Green's formula, Lemma 3.3 and (3.15),

$$
\left(\omega_{h}, \varepsilon(v)\right)=-\left(\operatorname{div} \omega_{h}, v\right)=-\left(\operatorname{div} \omega_{h}, \widetilde{Q}_{h} v\right)=\left(w, \widetilde{Q}_{h} v\right)
$$

so that

$$
\left|\left(\omega_{h}, \varepsilon(v)\right)\right| \leqq\|w\| \cdot\left\|\widetilde{Q}_{h} v\right\| \leqq C\|w\| .\|v\|_{1} .
$$

Together these estimates show

$$
\left\|\nabla \operatorname{tr} \omega_{h}\right\|_{H^{-1}(\Omega)} \leqq C\left(\left\|\bar{\omega}_{h}\right\|+\|w\|\right),
$$


which completes the proof in view of (3.16). Note that the expression in (3.17) could be estimated somewhat more precisely. In fact,

$$
\left|\left(\omega_{h}, \varepsilon(v)\right)\right| \leqq|(w, v)|+\left|\left(w, \widetilde{Q}_{h} v-v\right)\right| \leqq C\left(\|w\|_{H^{-1}(\Omega)}+h\|w\|\right)\|v\|_{1},
$$

which yields

$$
\left\|\operatorname{tr} \omega_{h}\right\| \mid \leqq C\left(\left\|\bar{\omega}_{h}\right\|+\|w\|_{H^{-3}(\Omega)}+h\|w\|\right) .
$$

Since we do not have the appropriate negative norm estimates at our disposal we have not been able to take advantage of this improved estimate.

THEOREM 3.1: The discrete problem (3.5) has exactly one solution $\left(u_{h}, \sigma_{h}\right) \in V_{h} \times H_{n}$ (with $\operatorname{tr} \sigma_{h}$ determined $u p$ to an additive constant $)$. With $(u, \sigma)$ the solution of (3.2) we have

$$
\begin{gathered}
\left\|u_{h}-u\right\| \leqq C h^{2}\|\sigma\|_{1}, \\
\left\|\sigma_{h}-\sigma\right\| \mid \leqq C h^{2}\|\sigma\|_{2},
\end{gathered}
$$

and

$$
\left\|u_{h}-u\right\|_{L_{\infty}} \leqq C h^{2} \log \frac{1}{h}\|\| \sigma \|_{2} \text {. }
$$

Proof: To prove existence it is sufficient to prove uniqueness. Thus letting $f=0$ and setting $v_{h}=u_{h}, \chi_{h}=\sigma_{h}$ in (3.5) we obtain

$$
\left\|\bar{\sigma}_{h}\right\|^{2}=-\left(u_{h}, \operatorname{div} \sigma_{h}\right)=0
$$

so that $\bar{\sigma}_{h}=0$. By Lemma 3.4 we conclude that $u_{h}=0$ and by Lemma 3.6 that $\operatorname{tr} \sigma_{n}-$ Const.

We now turn to the error estimates and being with (3.19). We have by (3.2a), (3.5a), and (3.6),

$$
\left(\operatorname{div} \sigma_{h}, v_{h}\right)=\left(\operatorname{div} \sigma, v_{h}\right)=\left(\operatorname{div} \Pi_{h} \sigma, v_{h}\right), \quad \forall v_{h} \in V_{h},
$$

so that $\operatorname{div}\left(\sigma_{h}-\Pi_{h} \sigma\right)=0$ by lemma 3.2 . Hence

$$
\left(\bar{\sigma}-\bar{\sigma}_{h}, \bar{\sigma}_{h}-\bar{\Pi}_{h} \bar{\sigma}\right)=-\left(u-u_{h}, \operatorname{div}\left(\sigma_{h}-\Pi_{h} \sigma\right)\right)=0,
$$

and we may conclude using Lemma 3.1 that

$$
\left\|\vec{\sigma}_{h}-\bar{\sigma}\right\| \leqq\left\|\bar{\sigma}-\overline{\Pi_{h} \sigma}\right\| \leqq C h^{s}\|\sigma\|_{s} \quad \text { for } \quad s=1,2 .
$$

In order to estimate $\operatorname{tr}\left(\sigma_{h}-\sigma\right)$ we use (3.21) and Lemma 3.6 to obtain from (3.22):

$$
\left\|\operatorname{tr}\left(\sigma_{h}-\Pi_{h} \sigma\right)\right\| \leqq C\left\|\bar{\sigma}_{h}-\bar{\Pi}_{h} \sigma\right\| \leqq C h^{2}\|\mid \sigma\|_{1} .
$$


Since by Lemma 3.1,

$$
\left\|\operatorname{tr}\left(\Pi_{h} \sigma-\sigma\right)\right\| \leqq\left\|\operatorname{tr}\left(\Pi_{h} \sigma-\sigma\right)\right\| \leqq C h^{2}\|\sigma\|_{2},
$$

this completes the proof of (3.19).

Turning now to the maximum-norm estimate for $u_{h}-u$ we note that

$$
\left(\bar{\sigma}_{h}-\bar{\sigma}, \chi_{h}\right)+\left(u_{h}-\widetilde{Q}_{h} u, \operatorname{div} \chi_{h}\right)=0, \quad \forall \chi_{h} \in H_{h} .
$$

Hence by Lemma 3.4 and (3.19),

$$
\left\|u_{h}-\widetilde{Q}_{h} u\right\|_{L_{\infty}(\Omega)} \leqq C \log \frac{1}{h}\left\|\bar{\sigma}_{h}-\bar{\sigma}\right\| \leqq C h^{2} \log \frac{1}{h}\|\sigma\|_{2} .
$$

In view of the maximum-norm estimate for $\widetilde{Q}_{h} u-u$ of Lemma 3.3 and the fact that $\varepsilon(u)=\bar{\sigma}$ this shows $(3.20)$.

It remains to consider the $L_{2}$ error estimate. We have in addition to (3.23),

$$
\left(\operatorname{div}\left(\sigma_{h}-\sigma\right), v_{h}\right)=0, \quad \forall v_{h} \in V_{h} .
$$

Hence Lemma 3.5 shows that

$$
\left\|u_{h}-\widetilde{Q}_{h} u\right\| \leqq C\left\{h\left\|\bar{\sigma}_{h}-\bar{\sigma}\right\|+h^{2}\left\|\operatorname{div}\left(\sigma_{h}-\sigma\right)\right\|\right\}
$$

By Lemma 3.2 we have

$$
\left\|\operatorname{div} \sigma_{h}\right\| \leqq C\|\operatorname{div} \sigma\|,
$$

so that using also (3.22) (with $s=1$ ) we may conclude

$$
\left\|u_{h}-\widetilde{Q}_{h} u\right\| \leqq C h^{2}\left(\|\sigma\|_{1}+\|\operatorname{div} \sigma\|\right) \leqq C h^{2}\|\sigma\|_{1} .
$$

Using once more Lemma 3.3 this completes the proof of (3.18) and thus of the theorem.

Given $f \in L_{2}(\Omega)^{2}$ we may again define $\left(T_{h}, S_{h}\right): L_{2}(\Omega)^{2} \rightarrow \stackrel{\circ}{V}_{h} \times H_{h}$ by $T_{h} f=u_{h}$, $S_{h} f=\sigma_{h}$ where $\left(u_{h}, \sigma_{h}\right)$ is the solution of the discrete problem (3.5). Letting similarly $(u, \sigma)$ denote the solution of the continuous problem (3.2) and setting $T f=u$ we now have the following lemma.

LEMma 3.7: The operator $T_{h}: L_{2}(\Omega)^{2} \rightarrow \stackrel{\circ}{V}_{h}$ is positive semidefinite on $L_{2}(\Omega)^{2}$, positive definite on $\dot{V}_{h}$ and satisfies

$$
\left\|T_{h} f-T f\right\| \leqq C h^{2}\|f\| .
$$

Proof: We may write the discrete problem

$$
\begin{gathered}
\left(\operatorname{div} S_{h} f, v_{h}\right)=-\left(f, v_{h}\right), \quad \forall v_{h} \in V_{h}, \\
\left(\widetilde{S_{h} f}, \bar{\chi}_{h}\right)+\left(T_{h} f, \operatorname{div} \chi_{h}\right)=0, \quad \forall \chi_{h} \in H_{h},
\end{gathered}
$$

vol. $15, \mathrm{n}^{\circ} 1,1981$ 
and it follows that

$$
\begin{gathered}
\left(f_{1}, T_{h} f_{2}\right)=-\left(\operatorname{div} S_{h} f_{1}, T_{h} f_{2}\right)=\left(\overline{S_{h} f_{1}}, \overline{S_{h} f_{2}}\right), \\
\forall f_{1}, f_{2} \in L_{2}(\Omega)^{2},
\end{gathered}
$$

from which we conclude that $T_{h}$ is selfadjoint and positive semidefinite. Let now $T_{h} f_{h}=0$ with $f_{h} \in \dot{V}_{h}$. We then have at once that $\overline{S_{h} f_{h}}=0$ and hence $\operatorname{div} S_{h} f_{h}=(1 / 2) \nabla \operatorname{tr} S_{h} f_{h}$ so that

$$
\left\|f_{h}\right\|^{2}=-\left(\operatorname{div} S_{h} f_{h}, f_{h}\right)=-\frac{1}{2}\left(\nabla \operatorname{tr} S_{h} f_{h}, f_{h}\right)=0,
$$

since $f_{h} \in \stackrel{\circ}{V}_{h}$, so that $T_{h}$ is positive definite on $\stackrel{\circ}{V}_{h}$. Finally, by Theorem 3.1 , and the regularity estimates (3.4),

$$
\left\|T_{h} f-T f\right\|=\left\|u_{h}-u\right\| \leqq C h^{2}\|\sigma\|_{1} \leqq C h^{2}\|f\|,
$$

which completes the proof.

\section{THE EVOLUTIONARY STOKES' EQUATIONS}

We shall finally consider the time-dependent Stokes' equations

$$
\left.\begin{array}{c}
u_{t}-\frac{1}{2} \Delta u+\nabla p-f \quad \text { in } \Omega \times R_{+}, \\
\operatorname{div} u=0 \text { in } \Omega \times R_{+}, \\
u=0 \text { on } \Gamma \times R_{+}, \\
u(., 0)=g \text { in } \Omega,
\end{array}\right\}
$$

with $\Omega$ again a convex plane domain with smooth boundary $\Gamma$. Let $(u, p)$ be a solution of this problem and set, with the notation of Section $3, \sigma=\varepsilon(u)-p \delta$. Then with $V$ and $H$ as in Section $3,(u, \sigma): R_{+} \rightarrow V \times H$ satisfies the following variational form of (4.1):

$$
\begin{gathered}
\left(u_{t}, v\right)-(\operatorname{div} \sigma, v)=(f, v), \quad \forall v \in V, \quad t \geqq 0, \\
(\bar{\sigma}, \bar{\chi})+(u, \operatorname{div} \chi)=0, \quad \forall \chi \in H, \quad t \geqq 0, \\
u(0)=g .
\end{gathered}
$$


With $V_{h}$ and $H_{h}$ the subspaces of $V$ and $H$ used above, we now pose as a corresponding semidiscrete problem: find $\left(u_{h}, \sigma_{h}\right): R_{+} \rightarrow V_{h} \times H_{h}$ such that

$$
\begin{gathered}
\left(u_{h, t}, v_{h}\right)-\left(\operatorname{div} \sigma_{h}, v_{h}\right)=\left(f, v_{h}\right), \quad \forall v_{h} \in V_{h}, \quad t \geqq 0, \\
\left(\bar{\sigma}_{h}, \bar{\chi}_{h}\right)+\left(u_{h}, \operatorname{div} \chi_{h}\right)=0, \quad \forall \chi_{h} \in H_{h}, \quad t \geqq 0, \\
u_{h}(0)=g_{h},
\end{gathered}
$$

where $g_{h}$ is an approximation of $g$ to be specified.

Recall from Section 3 the definition of the operator $\left(T_{h}, S_{h}\right): L_{2}(\Omega)^{2} \rightarrow \dot{V}_{h} \times H_{h}$ such that $\left(u_{h}, \sigma_{h}\right)=\left(T_{h} f, S_{h} f\right) \in \dot{V}_{h} \times H_{h}$ is the solution of the discrete stationary problem

$$
\begin{array}{cc}
\left(\operatorname{div} S_{h} f, v_{h}\right)+\left(f, v_{h}\right)=0, & \forall v_{h} \in V_{h}, \\
\left(\overline{S_{h} f}, \bar{\chi}_{h}\right)+\left(T_{h} f, \operatorname{div} \chi_{h}\right)=0, & \forall \chi_{h} \in H_{h} .
\end{array}
$$

Employing this notation, we find that the $u_{h}$-component of a solution of (4.3) has to belong to $\dot{V}_{h}$ and to satisfy

$$
T_{h} u_{h, t}+u_{h}=T_{h} f \quad \text { for } \quad t \geqq 0, \quad u_{h}(0)=g_{h} .
$$

Since $T_{h}$ is positive definite on $\dot{V}_{h}$ by Lemma 3.7 this problem admits a unique solution $u_{h}: R_{+} \rightarrow V_{h}$. With $u_{h}(t)$ given the equation $(4.3 b)$ may be used to determine $\bar{\sigma}_{h}(t)$ and then $(4.3 a)$ yields $\nabla \operatorname{tr} \sigma_{h}(t)$ so that $\sigma_{h}(t)$ is derived uniquely in $H_{h}\left[\operatorname{tr} \sigma_{h}(t)\right.$ up to an additive constant]. We have therefore demonstrated the existence and uniqueness part of the following theorem, which also contains error estimates corresponding to those of Theorem 2.1, under the assumption of a smooth solution. For defining the discrete initial data we shall use the operator $\tilde{Q}_{h}$ of Lemma 3.3.

THEOREM 4. 1: The discrete evolutionary problem (4.3) has a unique solution for $t \geqq 0$ (with $\operatorname{tr} \sigma_{h}$ unique up to an additive constant). If $u_{h}(0)=\widetilde{Q}_{h} g$ we have for $t>0$,

$$
\begin{gathered}
\left\|u_{h}(t)-u(t)\right\| \leqq C h^{2}\left\{\|\sigma(0)\|_{1}+\int_{0}^{t}\left\|\sigma_{t}\right\|_{1} d \tau\right\} \\
\left\|u_{h}(t)-u(t)\right\|_{L,(\Omega)} \leqq C h^{2} \log \frac{1}{h}\left\{\sup _{\tau \leqq t}\|\sigma(\tau)\|_{2}+\left(\int_{0}^{t}\left\|\sigma_{t}\right\|_{1}^{2} d \tau\right)^{1 / 2}\right\} \\
\left\|\bar{\sigma}_{h}(t)-\bar{\sigma}(t)\right\| \leqq C h^{2}\left\{\sup _{\tau \leqq t}\|\sigma(\tau)\|_{2}+\left(\int_{0}^{t}\left\|\sigma_{t}\right\|_{1}^{2} d \tau\right)^{1 / 2}\right\}
\end{gathered}
$$


and

$$
\begin{aligned}
& \left(\int_{0}^{t}\left\|\operatorname{tr} \sigma_{h}-\operatorname{tr} \sigma\right\|^{2} d \tau\right)^{1 / 2} \\
& \quad \leqq C h^{2}\left\{\sup _{\tau \leqq t}\|\sigma(\tau)\|_{2}+\int_{0}^{t}\left\|\sigma_{t}\right\|_{1} d \tau+\left(\int_{0}^{t}\left\|\sigma_{t}\right\|_{1}^{2} d \tau\right)^{1 / 2}\right\} .
\end{aligned}
$$

Proof: Denote by $\left(\tilde{u}_{h}, \tilde{\sigma}_{h}\right)=-\left(T_{h} \operatorname{div} \sigma, S_{h} \operatorname{div} \sigma\right)$ the "elliptic projection" of $(u, \sigma)$, the solution of the discrete stationary problem (3.5) with $f=-\operatorname{div} \sigma$ and set

$$
e_{h}=u_{h}-\tilde{u}_{h}, \quad \varepsilon_{h}=\sigma_{h}-\tilde{\sigma}_{h}, \quad \rho=u-\tilde{u}_{h} .
$$

We may then write the error equations in the form

$$
\begin{gathered}
\left(e_{h, t}, v_{h}\right)-\left(\operatorname{div} \varepsilon_{h}, v_{h}\right)=\left(\rho_{t}, v_{h}\right), \quad \forall v_{h} \in V_{h}, \\
\left(\bar{\varepsilon}_{h}, \bar{\chi}_{h}\right)+\left(e_{h}, \operatorname{div} \chi_{h}\right)=0, \quad \forall \chi_{h} \in H_{h} .
\end{gathered}
$$

Recall from theorem 3.1 that

$$
\|\rho(t)\|=\left\|u(t)-\tilde{u}_{h}(t)\right\| \leqq C h^{2}\|\sigma(t)\|_{1},
$$

and hence also

$$
\left\|\rho_{t}(t)\right\| \leqq C h^{2}\left\|\sigma_{t}(t)\right\| \|_{1},
$$

so that using lemma 3.3 ,

$$
\left\|e_{h}(0)\right\| \leqq\|\rho(0)\|+\left\|\widetilde{Q}_{h} u(0)-u(0)\right\| \leqq C h^{2}\|\sigma(0)\|_{1}
$$

Further we have

$$
\left\|\bar{\varepsilon}_{h}(0)\right\| \leqq C h^{2}\|\sigma(0)\|_{2}
$$

In fact, for $\chi_{h} \in H_{h}$, since $g=0$ on $\Gamma$, div $g=0$ in $\Omega$,

$$
\begin{aligned}
\left(\bar{\sigma}_{h}(0), \bar{\chi}_{h}\right)=-\left(u_{h}(0), \operatorname{div} \chi_{h}\right)=-\left(\widetilde{Q}_{h} g, \operatorname{div} \chi_{h}\right) \\
=-\left(g, \operatorname{div} \chi_{h}\right)=\left(\varepsilon(g), \bar{\chi}_{h}\right)=\left(\bar{\sigma}(0), \bar{\chi}_{h}\right),
\end{aligned}
$$

so that taking $\bar{\chi}_{h}=\bar{\sigma}_{h}-\overline{\Pi_{h} \sigma}$ and using Lemma 3.1,

$$
\left\|\bar{\sigma}_{h}(0)-\bar{\sigma}(0)\right\| \leqq\left\|\overline{\Pi_{h} \sigma}(0)-\bar{\sigma}(0)\right\| \leqq C h^{2}\|\| \sigma(0) \|_{2} .
$$

Since by Theorem 3.1,

$$
\left\|\overline{\tilde{\sigma}}_{h}(0)-\bar{\sigma}(0)\right\| \leqq C h^{2}\|\sigma(0)\|_{2},
$$

this shows (4.12). 
We now turn to the error estimates of the theorem and start with (4.4). By the error equations we obtain

$$
\frac{1}{2} \frac{d}{d t}\left\|e_{h}\right\|^{2}+\left\|\bar{\varepsilon}_{h}\right\|^{2}=\left(\rho_{t}, e_{h}\right) \leqq\left\|\rho_{t}\right\| \cdot\left\|e_{h}\right\|,
$$

so that by (4.10) and (4.11),

$$
\begin{aligned}
\left\|e_{h}(t)\right\|+\left(\int_{0}^{t}\left\|\bar{\varepsilon}_{h}\right\|^{2} d \tau\right)^{1 / 2} & \leqq C\left\{\left\|e_{h}(0)\right\|+\int_{0}^{t}\left\|\rho_{t}\right\| d \tau\right\} \\
& \left.\leqq C h^{2}\left\{\|\sigma(0)\|_{1}+\int_{0}^{t}\left\|\sigma_{t}\right\|_{1} d \tau\right\}\right) .
\end{aligned}
$$

Together with (4.9) this shows (4.4). The second term on the left is included for later reference.

In order to show the estimate for $\bar{\sigma}_{h}$, we differentiate $(4.8 b)$ to obtain

$$
\frac{1}{2} \frac{d}{d t}\left\|\bar{\varepsilon}_{h}\right\|^{2}+\left\|e_{h, t}\right\|^{2}=\left(\rho_{t}, e_{h, t}\right) \leqq \frac{1}{2}\left\|\rho_{t}\right\|^{2}+\frac{1}{2}\left\|e_{h, t}\right\|^{2},
$$

so that now by (4.10) and (4.12),

$$
\begin{aligned}
\left\|\bar{\varepsilon}_{h}(t)\right\|^{2}+\int_{0}^{t}\left\|e_{h, t}\right\|^{2} d \tau \leqq & \left\|\bar{\varepsilon}_{h}(0)\right\|^{2}+\int_{0}^{t}\left\|\rho_{t}\right\|^{2} d \tau \\
& \leqq C h^{4}\left\{\|\sigma(0)\|_{2}^{2}+\int_{0}^{t}\|\| \sigma_{t}\|\|_{1}^{2} d \tau\right\} .
\end{aligned}
$$

Since by Theorem 3.1,

$$
\left\|\bar{\sigma}(t)-\overline{\tilde{\sigma}}_{h}(t)\right\| \leqq C h^{2}\|\mid \sigma(t)\|_{2},
$$

this completes the proof of (4.6).

In order to estimate $\operatorname{tr}\left(\sigma_{h}-\sigma\right)$ we note that by Lemma 3.6 and $(4.8 a)$,

so that

$$
\text { || } \operatorname{tr} \varepsilon_{h}(t) \| \leqq C\left\{\left\|\bar{\varepsilon}_{h}(t)\right\|+\left\|e_{h, t}\right\|+\left\|\rho_{t}\right\|\right\},
$$

$$
\int_{0}^{t}\left\|\operatorname{tr} \varepsilon_{h}(\tau)\right\|^{2} d \tau \leqq C \int_{0}^{t}\left(\left\|\bar{\varepsilon}_{h}\right\|^{2}+\left\|e_{h, t}\right\|^{2}+\left\|\rho_{t}\right\|^{2}\right) d \tau .
$$

In view of (4.10), (4.13), and (4.14) this shows

$$
\begin{aligned}
& \left(\int_{0}^{t}\left\|\operatorname{tr} \varepsilon_{h}(\tau)\right\|^{2} d \tau\right)^{1 / 2} \\
& \qquad C h^{2}\left\{\|\sigma(0)\|_{2}+\int_{0}^{t}\left\|\sigma_{t}\right\|_{1} d \tau+\left(\int_{0}^{t}\left\|\sigma_{t}\right\|_{1}^{2} d \tau\right)^{1 / 2}\right\} .
\end{aligned}
$$

vol. $15, \mathrm{n}^{\circ} 1,1981$ 
Since by Theorem 3.1:

$$
\left\|\operatorname{tr}\left(\sigma(t)-\tilde{\sigma}_{h}(t)\right)\right\| \geqq C h^{2}\|\sigma(t)\|_{2},
$$

this completes the proof of (4.7).

As in the proof of Theorem 2.1, using Lemma 3.4 we have by (4.14),

$$
\begin{aligned}
& \left\|e_{h}(t)\right\|_{L_{\infty}(\Omega)} \leqq C \log \frac{1}{h}\left\|\bar{\varepsilon}_{h}(t)\right\| \\
& \qquad C h^{2} \log \frac{1}{h}\left\{\|\sigma(0)\| \|_{2}+\left(\int_{0}^{t}\left\|\sigma_{t}\right\| \|_{1}^{2} d \tau\right)^{1 / 2}\right\},
\end{aligned}
$$

and (4.5) then follows since by Theorem 3.1,

$$
\|\rho(t)\|_{L_{\infty}(\Omega)} \leqq C h^{2} \log \frac{1}{h}\|\sigma(t)\|_{2}
$$

The proof of the theorem is now complete.

It follows from (4.15) that if we had had at our disposal pointwise estimates in $t$ for $e_{h, t}$, we would have been able to avoid the integral on the left of (4.7). Such estimates may in fact be shown for $t$ bounded away from zero by the techniques of [17]. We shall not insist on this matter.

We shall now turn to error estimates for the homogeneous equation, i. e. the case $f=0$ in (4.1). In order to express the regularity of the solution $(u(t), \sigma(t))$ of (4.2) in this case, we introduce the eigenvalues $\left\{\lambda_{j}\right\}_{1}^{\infty}$ and $L_{2}$-orthonormal eigenfunctions $\left\{\varphi_{j}\right\}_{1}^{\infty}$ of the stationary Stokes' problem: Find $\varphi \in H_{0}^{1}(\Omega)^{2}$ such that for some $q \in L_{2}(\Omega)$,

$$
\begin{gathered}
-\Delta \varphi+\nabla q=\lambda \varphi \text { in } \Omega, \\
\operatorname{div} \varphi=0 \text { in } \Omega, \\
\varphi=0 \text { on } \Gamma .
\end{gathered}
$$

As in the elliptic case, $\lambda_{j} \rightarrow \infty$ for $j \rightarrow \infty$ and the $\varphi_{j}$ are smooth when $\Gamma$ is smooth (see [15]). For $s \geqq 0$ let $\dot{H}^{s}=\dot{H}^{s}(\Omega)$ be the space defined by the norm

$$
\|v\|_{\dot{H}^{s}}=\left(\sum_{j=1}^{\infty} \lambda_{j}^{s}\left(v, \varphi_{j}\right)^{2}\right)^{1 / 2}
$$

One can show that in the same way as in the elliptic case (cf. [5]), for $s$ a nonnegative integer, the norm in $\dot{H}^{s}$ is equivalent to the usual norm in $H^{s}(\Omega)^{2}$. It is 
easy to see that for initial data $g \in L_{2}(\Omega)^{2}$ with $\operatorname{div} g=0$ in $\Omega$ the $u$-component of the solution of (4.1) with $f=0$ is given by

$$
u(t)=\sum_{j=1}^{\infty} e^{-\lambda, t}\left(g, \varphi_{J}\right) \varphi_{J}
$$

and thus

$$
\|u(t)\|_{H^{s}} \leqq C t^{-(s-j) / 2}\|g\|_{H^{j}} \quad \text { for } \quad s \geqq j, \quad t>0 .
$$

We also notice that if $f=0$ then by (4.1), for $t>0$,

$$
\begin{gathered}
-\frac{1}{2} \Delta u+\nabla p=-u_{t} \quad \text { in } \Omega, \\
\operatorname{div} u=0 \text { in } \Omega, \\
u=0 \text { on } \Gamma .
\end{gathered}
$$

By the regularity result (3.4) for Stokes' problem quoted in Section 3 and by (4.16) we therefore have

$$
\left.\begin{array}{c}
\|\| \sigma(t)\|\|_{s-1} \leqq C\left\|u_{t}(t)\right\|_{s-2} \leqq C\left\|u_{t}(t)\right\|_{H^{s-2}} \leqq C\|u(t)\|_{H^{s}} \\
\text { for } s \geqq 2, \quad t>0 .
\end{array}\right\}
$$

Our first result for the homogeneous equation is the following analogue of Theorem 2.1 which deals with smooth solutions

Theorem 4.2: Consider the homogeneous equation and let $u_{h}(0)=\widetilde{Q}_{h} g$. Then for $t \geqq 0$,

$$
\begin{gathered}
\left\|u_{h}(t)-u(t)\right\| \leqq C h^{2}\|g\|_{H^{2}}, \\
\left\|u_{h}(t)-u(t)\right\|_{L_{\infty}(\Omega)} \leqq C h^{2} \log \frac{1}{h}\|g\|_{H^{3}},
\end{gathered}
$$

and

$$
\begin{gathered}
\left\|\bar{\sigma}_{h}(t)-\sigma(t)\right\| \leqq C h^{2}\|g\|_{H^{3}} \\
\left(\int_{0}^{t}\left\|\operatorname{tr} \sigma_{h}(\tau)-\operatorname{tr} \sigma(\tau)\right\|^{2} d \tau\right)^{1 / 2} \leqq C\left(1+t^{1 / 2}\right)\|g\|_{H^{3}}
\end{gathered}
$$

Proof: Let $u_{h}^{0}(t)$ be the solution of the discrete problem with $u_{h}^{0}(0)=P_{h} g$ where $P_{h}$ denotes the $L_{2}$ projection onto $\dot{V}_{h}$. Then following line by line the error analysis from [4] we find

$$
\left\|u_{h}^{0}(t)-u(t)\right\| \leqq C h^{2}\|g\|_{H^{2}} .
$$


Since $e_{h}^{0}=u_{h}^{0}-u_{h}$ solves the problem

$$
T_{h} e_{h, t}^{0}+e_{h}^{0}=0 \quad \text { for } \quad t \geqq 0, \quad e_{h}^{0}(0)=P_{h} g-\tilde{Q}_{h} g,
$$

we obtain

$$
\left\|e_{h}^{0}(t)\right\| \leqq\left\|e_{h}^{0}(0)\right\| \leqq\left\|\left(I-P_{h}\right) g\right\|+\left\|\left(I-\widetilde{Q}_{h}\right) g\right\| \leqq C h^{2}\|g\|_{2},
$$

which completes the proof of (4.19).

In order to show (4.21) and (4.22) we use the estimate of Theorem 4.1 together with the fact that by $(4.16)$ and $(4.18)$,

$$
\int_{0}^{t}\left\|\sigma_{t}\right\|_{1}^{2} d \tau \leqq C \int_{0}^{t} \sum_{j=1}^{\infty} \lambda_{j}^{4}\left(g, \varphi_{j}\right)^{2} e^{-2 \lambda, \tau} d \tau \leqq C\|g\|_{\dot{H}^{3}}^{2} .
$$

Finally, applying Lemma 3.4 to the equation

$$
\left(\bar{\sigma}_{h}-\bar{\sigma}, \chi_{h}\right)+\left(u_{h}-\bar{Q}_{h} u, \operatorname{div} \chi_{h}\right)=0, \quad \forall \chi \in H_{h},
$$

we find

$$
\left\|u_{h}(t)-\widetilde{Q}_{h} u(t)\right\|_{L_{\infty}(\Omega)} \leqq C \log \frac{1}{h}\left\|\bar{\sigma}_{h}(t)-\bar{\sigma}(t)\right\| \leqq C h^{2} \log \frac{1}{h}\|g\|_{\dot{H}^{3}},
$$

which in combination with ( $c f$. Lemma 3.3):

$$
\left\|\widetilde{Q}_{h} u(t)-u(t)\right\|_{L_{x}(\Omega)} \leqq C h^{2} \log \frac{1}{h}\|\sigma(t)\|_{2} \leqq C h^{2} \log \frac{1}{h}\|g\|_{H^{3}}
$$

shows (4.20).

Our final result concerns the homogeneous equation with non-smooth data. Here, as in Theorem 2.3, we use the $L_{2}$-projection $P_{h}: V \rightarrow \stackrel{\circ}{V}_{h}$ to define our discrete initial data.

THEOREM 4. 3: Consider the homogeneous equation and let $u_{h}(0)=P_{h} g$. Then for $t>0$,

$$
\begin{gathered}
\left\|u_{h}(t)-u(t)\right\| \leqq C h^{2} t^{-1}\|g\|, \\
\left\|u_{h}(t)-u(t)\right\|_{L_{\infty}(\Omega)} \leqq C h^{2} \log \frac{1}{h} t^{-3 / 2}\|g\|, \\
\left\|\bar{\sigma}_{h}(t)-\bar{\sigma}(t)\right\| \leqq C h^{2} t^{-3 / 2}\|g\|,
\end{gathered}
$$

and

$$
\|\| \operatorname{tr} \sigma_{h}(t)-\operatorname{tr} \sigma(t)\|\| \subseteq h^{2}\left(t^{-3 / 2}+t^{-2}\right)\|g\| .
$$


Proof: Since the solution operators $T_{h}$ and $T$ of the discrete and continuous stationary problems satisfy the properties of Lemma 3.7, and since (4.17) holds for the solution of the continuous problem we have by reproducing the proof in [4] for the case of the conventional parabolic problem,

$$
\left\|D_{t}^{j}\left(u_{h}-u\right)(t)\right\| \leqq C h^{2} t^{-1-j}\|g\| \quad \text { for } \quad j \geqq 0, \quad t>0,
$$

which in particular shows (4.23).

For the purpose of showing (4.25) we use again the elliptic projection $\left(\tilde{u}_{h}, \tilde{\sigma}_{h}\right)$ of the exact solution $(u, \sigma)$ and note that by $(4.8)$,

$$
\left\|\bar{\varepsilon}_{h}\right\|^{2}=-\left(\left(u_{h}-u\right)_{t}, e_{h}\right) .
$$

Here by (4.23), (4.9), (4.18), and (4.17),

$$
\begin{aligned}
\left\|e_{h}(t)\right\| \leqq\left\|u_{h}(t)-u(t)\right\|+\|\rho(t)\| & \\
& \leqq C h^{2} t^{-1}\|g\|+C h^{2}\|\sigma(t)\|\left\|_{1} \leqq C h^{2} t^{-1}\right\| g \|,
\end{aligned}
$$

so that using (4.27),

$$
\left\|\bar{\varepsilon}_{h}(t)\right\| \leqq C h^{2} t^{-3 / 2}\|g\| .
$$

Since by similar arguments

$$
\left\|\overline{\tilde{\sigma}}_{h}(t)-\bar{\sigma}(t)\right\| \leqq C h^{2}\|\sigma(t)\|_{2} \leqq C h^{2} t^{-3 / 2}\|g\|,
$$

this completes the proof of (4.25).

To demonstrate $(4.24)$ we recall $(4.8 b)$ which together with Lemma 3.4 shows that

$$
\left\|e_{h}(t)\right\|_{L_{\infty}(\Omega)} \leqq C \log \frac{1}{h}\left\|\bar{\varepsilon}_{h}(t)\right\| \leqq C h^{2} \log \frac{1}{h} t^{-3 / 2}\|g\| .
$$

Since

$$
\|\rho(t)\|_{L_{\infty}(\Omega)} \leqq C h^{2} \log \frac{1}{h}\|\sigma(t)\|_{2} \leqq C h^{2} \log \frac{1}{h} t^{-3 / 2}\|g\|,
$$

this proves (4.24).

Using finally the error equation $(4.8 a)$ we obtain by Lemma 3.6,

$$
\left\|\left|\operatorname{tr} \varepsilon_{h}(t)\left\|\mid \leqq C\left\{\left\|\bar{\varepsilon}_{h}(t)\right\|+\left\|\left(u_{h}-u\right)_{t}(t)\right\|\right\} \leqq C h^{2}\left(t^{-3 / 2}+t^{-2}\right)\right\| g \| .\right.\right.
$$

Using once more Theorem 3.1 we also find

$$
\left\|\left|\operatorname{tr}\left(\tilde{\sigma}_{h}(t)-\sigma(t)\right)\left\|\mid \leqq C h^{2}\right\| \sigma(t)\left\|_{2} \leqq C h^{2} t^{-3 / 2}\right\| g \|,\right.\right.
$$

which completes the proof of (4.26) and thus of the theorem. 


\section{REFERENCES}

1. S. Agmon, A. Douglis and L. Nirenberg, Estimates Near the Boundary for Solutions of Elliptic Partial Differential Equations Satisfying General Boundary Conditions, Comm. Pure Appl. Math., Vol. 12, 1959, pp. 623-727.

2. G. A. Baker, J. H. Bramble and V. Thomée, Single Step Galerkin Approximations for Parabolic Problems, Math. Comp., Vol. 31, 1977, pp. 818-847.

3. J. H. Bramble and J. Osborn, Rate of Convergence Estimates for Non-Selfadjoint Eigenvalue Approximations, Math. Comp., Vol. 27, 1973, pp. 525-549.

4. J. H. Bramble, A. H. Schatz, V. Thomée and L. B. Wahlbin, Some Convergence Estimates for Semidiscrete Galerkin Type Approximations for Parabolic Equations, S.I.A.M. J. Numer. Anal., Vol. 14, 1977, pp. 218-241.

5. J. H. Bramble and V. Thomée, Discrete Time Galerkin Methods for à Parabolic Boundary Value Problem, Annali di Matematica pura ed applicata, Vol. 101, 1974, pp. 115-152.

6. F. Brezzi, On the Existence, Uniqueness and Approximation of Saddle-Point Problems Arising from Lagrangian Multipliers, R.A.I.R.O., Anal. Numér., Vol. 2, 1974, pp. 129-151.

7. A. CAlderón and A. Zygmund, On the Existence of Certain Singular Integrals, Acta Math., Vol. 88, 1952, pp. 85-139.

8. G. Duvaut and J. L. Lions, Les inéquations en mécanique et en physique, Dunod, Paris, 1972.

9. R. Falk and J. Osborn, Error Estimates for Mixed Methods, Technical report, The Mathematics Research Center, University of Wisconsin-Madison, 1979.

10. C. JENSEN, A Mixed Finite Element Method with Curved Elements, Technical report, Department of Computer Science, Chalmers University of Technology, 1979.

11. C. Johnson, A Mixed Finite Element Method for Navier-Stokes' Equations, R.A.I.R.O., Anal. Numér., Vol. 12, 1978, pp. 335-348.

12. C. Johnson and B. Mercier, Some Equilibrium Finite Element Methods for TwoDimensional Elasticity Problems, Numer. Math., Vol. 30, 1978, pp. 103-116.

13. P. A. Raviart and J. M. Thomas, A Mixed Finite Element Method for 2 nd Order Elliptic Problems, Proc. of the Symposium on the Mathematical Aspects of the Finite Element Method, Rome, December, 1975.

14. R. Scholz, $L_{\infty}$-Convergence of Saddle-Point Approximation for Second Order Problems, R.A.I.R.O., Anal. Numér.,

15. R. Temam, Navier-Stokes' Equations, North Holland. Amsterdam, 1977.

16. J. M. Thомаs, Sur l'analyse numérique des méthodes d'éléments finis hybrides et mixtes, Thèse, Université Pierre-et-Marie-Curie, Paris, 1977.

17. V. Тноме́, Some Interior Estimates for Semidiscrete Galerkin Approximations for Parabolic Equations, Math. Comp., Vol. 33, 1979, pp. 37-62. 